\title{
Herméneutique et symbolique : le ta'wīl chez Ibn 'Arabī et quelques auteurs antérieurs
}

\section{Mohammed Chaouki Zine}

\section{(2) OpenEdition \\ 12 Journals}

Édition électronique

URL : http://journals.openedition.org/beo/80

DOI : $10.4000 /$ beo. 80

ISBN : 978-2-35159-316-5

ISSN : 2077-4079

\section{Éditeur}

Presses de l'Institut français du Proche-Orient

\section{Édition imprimée}

Date de publication : 1 septembre 2009

Pagination : 351-384

ISBN : 978-2-35159-143-7

ISSN : 0253-1623

\section{Référence électronique}

Mohammed Chaouki Zine, "Herméneutique et symbolique : le ta'wīl chez Ibn 'Arabī et quelques auteurs antérieurs », Bulletin d'études orientales [En ligne], Tome LVIII I Septembre 2009, mis en ligne le 01 septembre 2010, consulté le 10 décembre 2020. URL : http://journals.openedition.org/beo/80 ; DOI : https://doi.org/10.4000/beo.80 
HERMÉNEUTIQUE ET SYMBOLIQUE :

LE TA'WĪL CHEZ IBN ‘ARABĪ ET QUELQUES AUTEURS ANTÉRIEURS.

Mohammed Chaouki ZINE

IREMAM, Aix-en-Provence

INTRODUCTION

La science ('ilm) et la connaissance (ma'rifa) traversent l'œuvre d'Ibn 'Arabī de part en part. Peu d'études ont été consacrées à ces deux notions fondamentales. Notre objectif est de déterminer leurs significations respectives, leur identité et leur différence ainsi que leur apport symbolique et herméneutique.

Quand on parle de science et de connaissance à quoi se réfère-t-on? Comment ces deux notions ont-elles évolué dans l'histoire de la spiritualité musulmane ou soufisme (tașawwuf) ? Y a-t-il une unité doctrinale autour de leur sens ou bien ont-elles requis des significations différentes, voire divergentes en fonction de leur usage?

C'est autour de ces questions que nous tenterons de définir la valeur épistémologique et herméneutique de la science et de la connaissance chez Ibn 'Arabī(1165-1240). Généralement on traduit le vocable ta'wīl par interprétation ou herméneutique. Mais Ibn 'Arabī ne parle de l'interprétation ( $t a^{\prime} w i \bar{l}$ ) que pour critiquer ses fondements théoriques et ses usages théologiques et philosophiques, de même pour le symbolisme qui requiert chez lui le sens de correspondance ou relation analogique (munāsaba) entre la chose et ce qu'elle signifie.

Pourquoi prendre les notions de "herméneutique" et de "symbolisme" avec prudence? Tout simplement parce qu'elles n'ont pas le même apport étymologique et lexicographique que fournit la langue arabe. C'est en débroussaillant le champ notionnel de la doctrine d'Ibn 'Arabī que nous pouvons déceler ces implications anagogiques.

\section{1- L'HERMÉNEUTIQUE ET LE SYMBOLISME : PRÉLIMINAIRES THÉORIQUES ET ÉPISTÉMOLOGIQUES}

Sous le vocable "herméneutique" se dessine une histoire longue et une littérature féconde qu'il serait impossible de cerner entièrement. Voyons seulement les définitions qui ont été adoptées pour les comparer ensuite avec la notion de ta'wïl. L'herméneutique serait une critique interne des textes en mettant à jour leurs idées sous-jacentes : « Le mot 
"herméneutique", du grec hermeneia qui signifie interprétation, caractérise la discipline, les problèmes, les méthodes qui ont trait à l'interprétation et à la critique des textes ${ }^{1}{ }^{\prime}$.

Plus qu'une simple théorie, l'herméneutique recèle une valeur pratique qui consiste à employer des méthodes et des instruments philologiques, lexicographiques, sémantiques afin de découvrir la signification d'un mot, c'est-à-dire son origine, sa formation et son évolution : «L'herméneutique désigne en premier lieu une pratique guidée par un art. C'est ce qu'évoque déjà la formation du terme qui vient qualifier une technè. L'art dont il s'agit ici est celui de l'annonce, de la traduction, de l'explication et de l'interprétation et il renferme naturellement l'art de comprendre qui lui sert de fondement et qui est toujours requis là où le sens de quelque chose n'apparaît pas ouvertement ou sans équivoque ${ }^{2}$ ».

En d'autres termes, il y a interprétation là où il y a confusion et équivocité. Ceci nécessite alors une panoplie de méthodes et d'outils pour expliciter le sens du mot et le rendre clair et accessible. De ce point de vue, les racines étymologiques du terme "herméneutique" mettent en exergue plusieurs significations :

Hermeneus : ce vocable signifie « traduire ». La traduction a, en effet, dans l'histoire des textes sacrés et des œuvres humaines un rôle prépondérant. Plus qu'une simple adaptation d'une œuvre en langue différente, la traduction signifie avant tout la saisie du sens de ce qui a été dit : "Partout, l'herméneutique doit accomplir une telle transposition d'un monde à l'autre, du monde d'une langue étrangère à une autre qui nous est familière ${ }^{3}$ ».

Hermeneia: ce mot signifie en quelque sorte la traduction d'une idée, c'est-à-dire l'énonciation d'une pensée en donnant corps aux idées abstraites.

Hermeneuein : traduire, c'est déjà communiquer. En effet, le rôle de l'interprétation est de transmettre le vouloir-dire d'un auteur (ou un locuteur) à un lecteur (ou un auditeur). Platon associe cette transmission à l'art divinatoire, c'est-à-dire communiquer la volonté divine à celui qui devine son extension à travers les signes érigés dans le monde.

Ces significations étymologiques qui s'entremêlent et se complètent ont pris plusieurs directions en fonction de l'emploi qui leur a été attribué. Aristote ne prend que le sens logique de l'herméneutique en pariant sur la nécessité d'écrire un Peri Hermeneias ou les éléments qui composent la proposition attributive.

L'hermeneia ou la proposition traduit, chez Aristote, la pensée en mots proférés ou fixés dans un discours. Dans les Temps modernes, l'hermeneutica des Latins traduit la façon d'interpréter les textes sacrés. Ils parlent ainsi de ars interpretandi dont l'origine remonte jusqu'à Origène ${ }^{4}:$ " Le même texte peut être interprété selon quatre perspectives superposées : 1) dans son sens littéral (dit "historique" ou "somatique") qu'on atteint par des études grammaticales ; 2) dans un sens allégorique, héritage stoïcien, qui porte généralement sur les dogmes de l'Église ; 3) dans un sens tropologique ou moral, destiné à

1. Bernard DupuY, « Herméneutique », Encyclopaedia Universalis, 11, 1989, p. 362.

2. Hans-Georg GADAmER, La philosophie herméneutique, trad. Jean Grondin, Paris, PUF, 1996, p. 85.

3. Ibid., p. 86

4. Henri de Lubac, Exégèse médiévale. Les quatre sens de l'écriture (4 tomes), Paris, Aubier, 1959-1964. 
la conduite éthique du croyant ; 4) dans un sens anagogique ou mystique, appelé à révéler des vérités d'ordre eschatologique ${ }^{5} \gg$.

En d'autres termes, le texte comporte deux significations : le sens littéral et le sens figuré ou bien la lettre et l'esprit ou encore, en termes familiers aux soufis de l'époque classique, l'extérieur (zāhir) et l'intérieur (bāțin). Nous verrons plus tard que les deux aspects du texte ont suscité de violentes polémiques reflétant ainsi deux catégories de savants : les exotéristes (zāhiriyyūn) et les ésotéristes (bāținiyyūn).

Comme le rappelle J. Grondin ${ }^{6}$, l'herméneutique comme néologisme fut introduite vers 1629 par J. C. Dannhauer et subit une évolution sémantique importante en ayant trois fonctions :

1- La subtilitas intellegendi qui consiste à rendre le texte intelligible et tente d'éclaircir un passage obscur pour une meilleure compréhension du texte.

2- La subtilitas explicandi qui ajoute à la compréhension du sens une explication éclairante portant sur la structure langagière du texte.

3- La subtilitas applicandi qui met en application (en pratique) le sens du texte.

Ces trois fonctions ont fait l'objet de commentaires, d'appropriations, voire de divergences entre ceux qui se contentent de l'explication littérale et grammaticale du texte et ceux qui font triompher l'interprétation ésotérique.

Outre les deux approches, la dimension pratique traduit le savoir canonique en vertus et œuvres. Ceci explique qu'il n'y a pas de théorie universelle de l'interprétation unanimement reconnue, mais simplement des procédures ou des méthodes d'analyse: «Il n'y a pas d'herméneutique générale, pas de canon universel pour l'exégèse, mais des théories séparées et opposées concernant les règles de l'interprétation ${ }^{7}$ ».

Que l'herméneutique soit un archipel d'interprétations, cela signifie qu'elle stipule une multitude de lectures, d'approches et d'appréciations, objectives pour les uns, subjectives pour les autres. Elle se sert d'instruments logiques ou de raisonnements intuitifs afin de transposer les choses réelles en symboles. Elle a pour vocation de déchiffrer ces symboles et de saisir le lien qu'ils entretiennent avec le monde phénoménal. D'où l'inextricable relation entre l'herméneutique en tant que méthode ayant pour objet l'interprétation des signes (le texte, la nature, les modes d'expression, etc.) et le symbolisme qui porte sur ce que ces signes veulent dire.

Comme nous l'avons fait avec l'herméneutique, nous nous contenterons de quelques jalons méthodologiques du symbolisme. Celui-ci est caractérisé par la pluralité des symboles qui désignent quelque chose: "Un symbole ne signifie pas : il évoque et focalise,

\footnotetext{
5. Jean GRondin, « Herméneutique », p. 1130, Encyclopédie philosophique universelle, dirigée par André Jacob, II- Les notions philosophiques, vol. 1, Paris, PUF, 1990, 1998.

6. Ibid. ; v. aussi J. GRondin, L’universalité de l'herméneutique, Paris, PUF, 1993.

7. Paul Ricœur, De l'interprétation. Essai sur Freud, Paris, Seuil, 1965, p. 35.
} 
assemble et concentre, de façon analogiquement polyvalente, une multiplicité de sens qui ne se réduisent pas à une seule signification ni à quelques-unes seulement ${ }^{8}$ ".

La pluralité des significations est proportionnelle à la multiplicité des choses dans le monde. Derrière cette apparente diversité se dresse un ordre qui relie les choses les unes aux autres en vertu d'un rapport analogique ou corrélatif : "Ces deux hypothèses initiales : l'existence de l'ordre dans l'univers et la logique de l'analogie, si on les admet, suffisent, en effet, à fonder la symbolique générale et à étudier ses formes les plus diverses [...] La symbolique s'édifiera peu à peu à partir de l'étude du symbolisme, c'est-à-dire de "l'art de symboliser", de l'usage et de l'expérience des symboles ${ }^{9} »$. Ainsi, on peut faire la différence entre la symbolique qui est la science du (ou le discours sur le) symbolisme et celui-ci qui est l'usage (scientifique, métaphysique, philosophique ou mystique) des symboles et «l'on peut définir le symbole, avec A. Lalande, comme tout signe concret évoquant, par un rapport naturel, quelque chose d'absent ou d'impossible à percevoir ${ }^{10} »$.

Pour une analyse détaillée et fort documentée sur les diverses modifications du sens du symbole et de ses altérations à travers les époques, nous renvoyons au chapitre 1 de $L a$ science des symboles ${ }^{11}$. Sous le mot symbole, une multitude de notions apparaissent et qui prêtent à confusion comme l'avait remarqué Gilbert Durand : "Quoi qu'il en soit, "image", "signe", "allégorie", "symbole", "emblème", "parabole", "mythe", "figure”, "icône", "idole", etc., sont utilisés indifféremment l'un pour l'autre par la plupart des auteurs »"

Il est hors de propos de s'attarder longtemps sur la signification de chaque notion, mais remarquons, avec G. Durand, que les deux mots qui sont généralement confondus sont l'allégorie et le symbole. Bien qu'ils ne soient pas entièrement disjoints à l'époque médiévale, allégorie et symbole semblent remplir deux fonctions distinctes. La première a rapport avec le discours et la pensée par la transposition des images en idées, et c'est pour cette raison qu'elle est fondée sur la métaphore, alors que le second entretient une relation étroite avec l'impression qu'il laisse chez le sujet qui saisit la signification.

Alain disait à juste titre « le symbole est au sentiment ce que l'allégorie est à la pensée ». Cependant la tâche commune imputée à ces deux notions est la reconduction d'une chose sensible à son image abstraite: "Le symbole est, comme l'allégorie, reconduction du sensible, du figuré au signifié, mais en plus il est par la nature même du signifié inaccessible, épiphanie, c'est-à-dire, par et dans le signifiant, de l'indicible. L'on voit derechef quel va être le domaine de prédilection du symbolisme: le non-sensible sous toutes ses formes: inconscient, métaphysique, surnaturel et sur-réel ${ }^{13}$. » Le propre du symbole est de rendre

\footnotetext{
8. René Alleau, La science des symboles, Paris, Payot, 1976, p. 12-13

9. Ibid., p. 15-16

10. Gilbert Durand, L'imagination symbolique, Paris, PUF, 1964, col. «Initiation philosophique », p. 7

11. R. Alleau, op. cit., chapitre 1 « Origine et sémantique du mot "symbole" ».

12. G. DURAND, op. cit., p. 3.

13. Ibid., p. 7-8.
} 
visible ce qui est caché : «Le symbole est donc une représentation qui fait apparaittre un sens secret, il est l'épiphanie d'un mystère ${ }^{14}$. »

Comme son étymologie l'indique, le symbole (sumbolon) implique toujours le rassemblement de deux moitiés, signe et signifié, c'est-à-dire la face visible et la face invisible telle la lune durant sa phase bimensuelle. Le sumbolon est le signe de reconnaissance de cette lune sous sa phase initiale (croissant de lune) pour identifier le début du mois de jeûne (ramaḍān) et le début du jeûne : « Mangez et buvez jusqu'à ce que se distingue, pour vous, le fil blanc de l'aube du fil noir de la nuit. Puis accomplissez le jeûne jusqu'à la nuit » (Cor. 2/187).

Le symbole est, de ce point de vue, indice de la distinction entre deux aspects de la même réalité : le jour et la nuit (pour la journée), le visible (šahāda) et le caché (ǵayb) pour l'existence, etc. Cet aspect double de la réalité est caractérisé plus par la corrélation que par l'antinomie comme pourraient laisser croire les interprétations étourdies qui mettent l'extérieur (zāhir) ou la Loi (šarīa) aux antipodes de l'intérieur (bāṭin) ou la Réalité ésotérique (haqiqa) ${ }^{15}$. Ces idées ont fait l'objet de commentaires critiques de la part d'Ibn 'Arabī comme nous allons le découvrir ultérieurement.

A la lumière de ces définitions et délimitations théoriques, nous étudierons en premier lieu les approches contemporaines de l'herméneutique d'Ibn 'Arabī. Les noms de Corbin, Nașr H. Abū Zayd, Munșif 'Abdelhaqq et Dahabī font ici autorité. Nous examinerons ensuite le ta'wïl chez les prédécesseurs d'Ibn 'Arabī. Nous tenterons enfin de définir les implications herméneutiques et symboliques de la science et de la connaissance chez notre auteur.

\section{2- L'INTERPRÉTATION CONTEMPORAINE DE L'HERMÉNEUTIQUE D'IBN “ARABĪ : UN “CONTRESENS” ÉPISTÉMOLOGIQUE}

Comme nous pouvons le constater à propos de la théorie de l'unicité de l'être (wahdat al-wuğūd) utilisée à mauvais escient ${ }^{16}$, le ta'wīl a été, à son tour, l'objet de commentaires qui varient entre l'imprudence théorique et la misère méthodologique, à quelques exceptions près. Nous assistons à l'élaboration de ce qu'on pourrait appeler « un contresens épistémologique ", le résultat d'un survol rapide des textes ou d'une application non appropriée de concepts externes à la visée fondamentale de la doctrine de notre auteur.

Avant d'exposer certains exemples, voyons tout d'abord l'explication que Henry Corbin donne au ta'wīl d'Ibn 'Arabī, du fait qu'il était parmi les premiers spécialistes à se pencher sur les problèmes de l'imagination, du symbolisme et de l'herméneutique spirituelle.

\footnotetext{
14. Ibid., p. 9

15. On traduit généralement haqīqa par « vérité ». Dans le contexte de la mystique musulmane, elle pourrait être traduite par « réalité ésotérique ».

16. Une littérature contemporaine sur cette notion se propage à une grande allure comme le montrent les dizaines, voire les centaines d'études qui ont pris pour sujet d'analyse et de comparaison l'unicité de l'être chez Ibn 'Arabī. À titre d'exemple v. Abū l-'Alā Afī̄ī, The Mystical philosophy of Muhyid Dīn-Ibnul 'Arabī, Cambridge University Press, 1939; Ḥassan QARīB AlLĀH Falsafat wahdat al-wuğūd (La philosophie de l'unicité de l'être), Beyrouth, al-Kutub al-ḥadīta, 1997 ; Suhaila TARĞUMAN, Nazariyyat waḥdat al-wuğūd bayna Ibn 'Arabī wa al-Ǧìlì : dirāsa tahlīliyya, naqdiyya, muqārina (La théorie de l'unicité de l'être entre Ibn 'Arabī et al-Ǧillī : étude analytique, critique et comparative), Beyrouth, éd. alBouraq, 2002.
} 
Selon H. Corbin, il ne peut y avoir de dissociation entre l'herméneutique et l'ésotérisme. Toute interprétation vise le sens profond du texte par-delà son aspect apparent qui est langage : «Le ta'wïl présuppose la floraison des symboles, l'organe de l'imagination active qui simultanément les fait éclore et les perçoit [...]. Par essence, le ta'wïl ne peut tomber dans le domaine des évidences communes; il postule un ésotérisme ${ }^{17}$. $"$

H. Corbin fait la distinction entre l'allégorie et le symbole. Il attribue à l'allégorie une opération rationnelle, alors que le symbole s'ouvre sur plusieurs plans de l'être: "L'initiation au ta'wīl est naissance spirituelle (wilāda rūhāniyya). Parce qu'ici, comme chez tous ceux qui l'ont pratiqué dans le christianisme, c'est-à-dire ceux qui n'ont point confondu le sens spirituel avec l'allégorie, le ta'wīl fait pénétrer dans un nouveau monde, accéder à un plan supérieur de l'être ${ }^{18}$."

La distinction entre l'allégorie et le symbole est une invention récente. Bien qu'elle soit pertinente sur le plan épistémologique, cette séparation tombe cependant dans un anachronisme comme le laisse entendre ce texte de Jean Pépin: «On a pris aujourd'hui l'habitude de distinguer nettement entre allégorie et symbole, comme entre l'artifice didactique et la spontanéité de la vie. Pour que cette distinction, d'ailleurs fondée, puisse être prise en considération à propos de Dante, il faudrait, semble-t-il, qu'elle fût entrée dans les mœurs à son époque. Or c'est ce qui n'apparaît en rien. La définition ancienne et médiévale de l'allégorie est si large qu'elle convient à presque toutes les variétés de l'expression figurée, et en tout cas à l'expression symbolique ${ }^{19}$. "

Dans son approche de l'expérience de l'art, Gadamer rappelle de son côté que «les deux concepts d'allégorie et de symbole ont beau appartenir à des sphères différentes, ils n'en sont pas moins proches l'un de l'autre, non seulement en vertu de la structure qui leur est commune, celle de la représentation de quelque chose par autre chose, mais également parce qu'ils trouvent l'un et l'autre dans le champ du religieux leur application privilégiée ${ }^{20} »$. La distinction initiale, d'après Gadamer, fait de l'allégorie une figure de rhétorique et un élément qui appartient au discours (logos), et du symbole une réalité qui désigne elle-même dans son manifestation phénoménale. La fonction des deux concepts reste identique en partant du substrat sensible pour accéder à l'intelligible : « Le symbolon reçoit ici une fonction anagogique ; il oriente l'esprit et l'élève à la connaissance du divin - tout comme l'expression allégorique introduit à une signification "supérieure". La démarche allégorique de l'interprétation et la démarche symbolique de la connaissance s'imposent pour la même raison : il n'est pas possible de connaître le divin autrement qu'à partir du sensible ${ }^{21}$. »

Gadamer remarque qu'il y eut une dégradation du sens de l'allégorie, celle-ci étant reléguée à une simple convention ou expression dogmatique de la chose religieuse. Quant

17. Henry Corbin, L’imagination créatrice dans le soufisme d'Ibn 'Arabī, Paris, Flammarion/Aubier, 1993, p. 19

18. Ibid., p. 29

19. Jean PépIN, Dante et la tradition de l'allégorie, Paris, Vrin, 1970, p. 15-16.

20. Hans-Georg GADAMER, Vérité et méthode : les grandes ligne d'une herméneutique philosophique, traduction par Pierre Fruchon, Jean Grondin et Gilbert Merlio, Paris, éditions du Seuil, 1996 (« L’ordre philosophique »), p. 90.

21. Ibid. 
au symbole, il a été érigé en réalité métaphysique, supérieure et positive de surcroît. Mais le symbole vit de la tension entre la forme et l'essence, ou entre l'expression et le contenu : "Cette absence d'adéquation entre forme et essence reste constitutive du symbole dans la mesure où sa signification renvoie au-delà de ce qui tombe sous les sens. C'est de cette inadéquation que naît le caractère flottant, d'indécision entre forme et essence, qui est propre au symbole ${ }^{22}$.»

L'opération procédée par $\mathrm{H}$. Corbin vise à briser les barrières psychologiques et doctrinales qui s'interposent entre le soufisme d'Ibn 'Arabī et le chiisme «c'est qu'Ibn 'Arabī fut lui-même un grand maître en ta'wīl - on le verra à l'œuvre au cours de ce livre et qu'il est impossible de mentionner le ta'wïl sans parler du chiisme dont le ta'wïl est un principe scripturaire fondamental ${ }^{23}$.»

Le propre du ta'wīl est, de ce point de vue, de reconduire les données littérales à ce qu'elles symbolisent et "prononcer le mot ta'wìl, c'est d'une manière ou d'une autre éveiller certaines résonances avec le chiisme, dont le principe scripturaire fondamental est que tout exotérique (zāhir) a un ésotérique (bāțin) ${ }^{24} »$.

H. Corbin érige le ta'wīl en loi universelle occultant, par là, les différences de taille qui existent entre le soufisme akbarien et la pensée chiite. C'est ce qui ressort de l'observation de William Chittick qui remarque que $\mathrm{H}$. Corbin fait du ta'wïl une pierre angulaire de la doctrine d'Ibn 'Arabī, négligeant que ce mot n'avait pas à l'époque d'Ibn 'Arabī une connotation positive ${ }^{25}$.

Par ailleurs, le ta'wïl ne peut être établi comme étant une norme universelle si on croit le philosophe Paul Ricœur, spécialiste en la matière. Or le livre de H. Corbin tente d'instaurer cette règle qui transcende les interprétations locales et divergentes: «En fait, tout le concept métaphysique de l'Imagination se trouve engagé dans l'instauration de ce monde intermédiaire. Toutes les réalités essentielles de l'être (haqā'iq al-wuğūd) y sont manifestées en Images réelles; et pour autant qu'une chose manifestée aux sens ou à l'intellect, possède une signification qui, en dépassant la simple donnée, fait de cette chose un symbole, et pour autant qu'elle exige ainsi une herméneutique (ta'will), la vérité symbolique de cette chose implique une perception au plan de l'imagination active ${ }^{26}$. »

Comme le songe, l'imagination nécessite un mode de transposition symbolique : « C'est parce que l'être révélé est imagination, qu'une herméneutique des formes manifestées en lui est nécessaire, c'est-à-dire un ta'wīl qui "reconduise" (selon l'étymologie du mot ta'wīl) ces formes à leur vraie réalité. Non seulement le monde du rêve mais le monde que nous

22. Ibid., p. 95.

23. H. CoRBIn, op. cit., p. 30.

24. Ibid., p. 45 et 68.

25. W. Cнiтtick, The Sufi Path of Knowledge, New York, SUNY, 1989, p. 199.

26. H. Corbin, op. cit., p. 147, cf. p.150. 
appelons communément le monde de la veille, tous deux ont même et égal besoin d'une herméneutique ${ }^{27}$. "

Cette universalité va affecter l'ensemble des écrits de H. Corbin. Elle met le ta'wīl dans un rapport concentrique avec l'imagination et le symbolisme. En d'autres termes, l'imagination est un phénomène global qui a pour organe d'expression le ta'wïl. Ce dernier englobe, à son tour, le symbolisme qui emploie les symboles à des fins initiatiques et spirituelles: "En bref, parce qu'il y a de l'imagination, il y a du ta'wïl; parce qu'il y a du ta'wīl, il y a du symbolisme; parce qu'il y a du symbolisme, il y a deux dimensions dans les êtres ${ }^{28}$. »

Pour résumer l'idée de H. Corbin, nous pouvons dire que grâce au ta'wïl les choses dans le monde sensible deviennent des symboles dans le monde imaginal. Elles ont, du point de vue symbolique, deux faces, l'une est tournée vers le sensible et se nomme "chose", "objet", "matière", etc., l'autre est tournée vers l'imaginal et s'appelle "symbole", "image", "idée", etc. Bref, c'est l'imagination comme mode d'être et mode de connaître qui justifie l'existence du ta'wil selon H. Corbin ${ }^{29}$.

Nașr Ḥāmid Abū Zayd n'est pas du même avis, car l'imagination (hayāl) ne constitue pas uniquement un élan de création, mais un obstacle à la véritable science. D’où la nécessité du ta'wīl qui va de l'extérieur grossier à l'intérieur subtil pour saisir la science authentique ${ }^{30}$. L'imagination n'est qu'un point de jonction entre le sensible et l'intelligible. Elle ne peut être érigée en mode supérieur de perception. Le véritable ta'will d'après Abū Zayd est celui qui s'identifie au dévoilement intuitif (kašf), c'est-à-dire saisir la chose telle qu'elle est en elle-même.

Or H. Corbin pense que sans imagination, le ta'wïl ne peut s'opérer comme transfiguration des choses en images : "On n'interprète pas ce qui n'a rien à vous apprendre, ne signifie rien de plus que ce qu'il est. C'est parce que le monde est imagination théophanique, qu'il est constitué d"“apparitions" demandant à être interprétées et dépassées ${ }^{31}$. »

La thèse de H. Corbin est justifiée par le hadith prophétique «Les gens dorment et lorsqu'ils meurent ils se réveillent ${ }^{32}$ ». Ainsi, l'homme demeure constamment dans le monde imaginal et utilise le ta'wil pour transmuer les choses sensibles en symboles afin

\footnotetext{
27. Ibid., p. 160.
}

28. Ibid., p. 161.

29. H. Corbin, Face de Dieu, Face de l'homme. Herméneutique et soufisme, Paris, Flammarion, 1983, p. 43, 45 et 46.

30. N. H. Abū Zayd, Falsafat al-ta'wīl. Dirāsa fì ta'wīl al-Qur'ān 'inda Muhyiddīn Ibn 'Arabī (La philosophie herméneutique. Etude sur l'interprétation du Coran chez Muhyiddīn Ibn 'Arabī), Beyrouth-Casablanca, éd. al-Markaz al-țaqāfī al-'arabī, $3^{e}$ éd., 1996, p. 227.

31. H. CoRBIN, L'imagination créatrice, op. cit., p. 161.

32. 'Alğūnī, Kašf al-hafā' (Le dévoilement du caché), II, p. 312. 
de les saisir et les comprendre. Abū Zayd revient pour cautionner cette idée, à savoir l'importance de l'imagination (ou le songe) pour procéder au ta'wīl ${ }^{33}$.

Qu'est-ce que le ta'wīl pour Abū Zayd?

D'une part, le ta'wīl serait, d'après lui, une méthode philosophique (manhağ falsafī) « qui régit la pensée d'Ibn 'Arabī au niveau de l'être et du Coran ensemble, car ils sont deux faces de la même et unique réalité ${ }^{34}$ ». Employer l'expression "méthode philosophique" n'est pas approprié dans le contexte du ta'wìl d'Ibn 'Arabī. Abū Zayd semble employer cette expression à cause de l'intérêt qu'il porte à la théorie philosophique de l'herméneutique développée par Hans-Georg Gadamer ${ }^{35}$.

D'autre part, le ta'wil est appréhendé comme la découverte d'une "cryptologie" inhérente au texte, une dimension "crypto-coranique" dirions-nous : "Le ta'wil signifie, de ce point de vue, la découverte d'un "chiffre" divin et la compréhension du Coran à la lumière de ce "chiffre", c'est-à-dire le comprendre comme étant un ensemble de symboles désignant les réalités de l'être et de l'homme ${ }^{36}$. » Abū Zayd emprunte apparemment la notion du "chiffre" à $\mathrm{H}$. Corbin ${ }^{37}$, d'autant plus que le mot désigne une sorte de codage secret, ce qui trahit la conception d'Abū Zayd qui se veut prudente face aux tendances ésotéristes.

Enfin, le ta'wïl est défini à partir de sa racine étymologique qui fait coïncider l'origine des choses et leur destinée.

Ces dimensions cosmogoniques et téléologiques (ou eschatologiques) caractérisent l'œuvre d'Ibn 'Arabī de fond en comble: «Le ta'wīl chez Ibn 'Arabī est de connaître la réalité de la chose et sa destinée ( $m a^{\prime}$ 'al $)$, c'est-à-dire son origine d'où elle procède et vers laquelle elle retourne. Sur le plan ontologique, le ta'wîl est le passage de l'extérieur sensible à l'intérieur spirituel et, sur le plan scripturaire, il est le dépassement de la langue humaine et conventionnelle vers la langue divine et absolue. En ce sens, le ta'wïl ne signifie pas la négation du zāhir, mais le point de départ, car le zāhir représente la coque extérieure du bātin ou son apparence ${ }^{38}$. "

De même en ce qui concerne la définition de Munsif 'Abdelhaqq : «Le ta'wïl chez Ibn 'Arabī - qu'il nomme ailleurs l'interprétation des rêves (ta'bīr) ou la métaphore (mağāa $z$ -

\footnotetext{
33. Abū Zayd, N. H., op. cit., p. 228.

34. Ibid., p. 230.

35. Cf. Abū Zayd, Iškāliyāt al-qirā’a wa āliyāt al-ta'wīl (Problèmes de lecture et instruments d'interprétation), Le Caire, éd. al-Markaz, 1991.

36. Abū Zayd, Falsafat al-ta'wīl, op. cit., p. 286.

37. H. CORBIN, op. cit., p. 19 : « Le symbole annonce un autre plan de conscience que l'évidence rationnelle; il est le “chiffre" d'un mystère... » et p. 161.

38. Abū Zayd, op. cit., p. 383.
} 
ne se dissocie pas de la communication : il signifie le passage de l'extérieur (l'expression apparente) à l'intérieur ou ce que l'auditeur leur croit ainsi ${ }^{39}$. "

Contrairement à Abū Zayd dont l'explication du ta'wīl d'Ibn 'Arabī s'est contentée de déceler les correspondances cosmologiques et anthropologiques, l'entreprise de M. 'Abdelhaqq met l'accent sur l'aspect sociologique et linguistique du ta'wïl : "Le terrain social explique de prime abord l'émergence de l'opération herméneutique ${ }^{40}$ ", dans la mesure où les interactions sociales sont préalablement symboliques, c'est-à-dire qu'elles s'opèrent au niveau du langage. Les relations humaines sont de nature "interprétative", car «l'auditeur qui ne parvient pas à expliquer les intentions du locuteur recourt alors à l'interprétation ${ }^{41} »$.

Sur le plan épistémologique, M. 'Abdelhạq pense que le ta'wìl est, structurellement, fondé sur l'hypothèse (ihtimāl) et l'opinion (zann), jamais sur la certitude, une idée partagée par l'instigateur de la critique de la raison arabe Muhammad 'Abid el-Ǧabirī ${ }^{42}$.

Certes, le ta'wīl se fonde sur la diversité des approches, ce qui donne crédit à l'opinion personnelle. Mais cette définition ne s'applique pas à la doctrine d'Ibn 'Arabī pour trois raisons :

1- L'opinion, l'hypothèse et l'effort individuel sont du ressort de la spéculation.

2- Le ta'wīl occulte la nature saine de la foi (ìmān).

3- Le ta'wīl est traduit dans la doctrine d'Ibn 'Arabī par d'autres notions impliquant la saisie intuitive : dévoilement (kašf), aspiration (himma), élection spirituelle (ihtișāṣ), etc.

Ces points feront ultérieurement l'objet d'un exposé détaillé. La lecture la plus audacieuse mais bourrée de contresens est celle de Muhammad Ḥusayn al-Dahabī dans son ouvrage al-Tafsìr wa al-mufassirūn (L'exégèse et les exégètes, 2 vol.). Ce qui nous intéresse ici est son opinion sur l'interprétation soufie du Coran. Malencontreusement, son opinion fait dire au texte de notre auteur ce qu'il n'a pas expressément dit. Nous faisons allusion à la wahdat al-wuğūd érigée en norme universelle pour lire et comprendre le texte coranique.

C'est ce qui ressort de l'analyse de Dahabī des Futūhāt et des Fuṣūṣ al-hikam. En effet, la théorie de l'unicité de l'être a entraîné cet auteur dans des explications hâtives et dangereusement outrageantes: "Nous le voyons [c.-à-d. Ibn 'Arabī] appliquer plusieurs versets coraniques sur ses théories mystiques et philosophiques ${ }^{43}$ " ou encore "Nous voyons aussi que dans son commentaire du Coran, Ibn 'Arabī est influencé par la théorie de l'unicité de l'être, la théorie la plus importante sur laquelle est fondé son soufisme. Dans la

39. M. 'Abdelhạq, al-Kitāba wa al-tağriba al-șūfiyya (L'écriture et l'expérience mystique), Rabat, éd. Okaz, 1988, p. 117.

40. Ibid., p. 118.

41. Ibid.

42. M. 'A. el-Ǧabrī, Bunyat al-'aql al-'arabī (La structure de la raison arabe), Beyrouth-Casablanca, éd. Markaz, 1991("Naqd al-'aql al-'arabī», 2), p. 300-302.

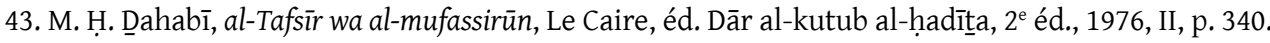


plupart des cas, il explique les versets à la lumière de cette théorie jusqu'à ce qu'il s'écarte du sens voulu par Dieu ${ }^{44} »$.

Cet amalgame se contente de survoler le texte sans l'approfondir réellement: «Ce genre de commentaire fondé sur la théorie de l'unicité de l'être est inadmissible quel que soit son promoteur ${ }^{45}$. » La même sentence, qui fait grief, revient tout au long des pages consacrées à l'herméneutique soufie et en particulier au commentaire d'Ibn 'Arabī des versets. Voici, par exemple, un passage qui ne comporte aucune valeur scientifique : «Du point de vue de l'unicité de l'être, et dans la plupart des cas, il abuse dans l'interprétation afin que le verset s'accorde avec cette théorie. Je pense que cette méthode exégétique est pernicieuse. Elle substitue à ce que Dieu veut dire dans ses versets des idées inhérentes à sa doctrine ${ }^{46}$. »

Ce genre de jugement ne présente pas les doctrines de façon équitable et impartiale. Il induit surtout le lecteur en erreur, celui qui n'est pas familiarisé avec le langage mystique et, en particulier, la terminologie soufie. Il est donc regrettable de se livrer à ce genre de lectures qui pervertissent notre compréhension de l'héritage herméneutique du soufisme.

Nous pouvons conclure cette partie en disant que le ta'wīl dans la pensée arabe contemporaine a fait l'objet d'analyses et de comparaisons qui s'éloignent dans la plupart des cas de l'objectif préalablement esquissé. Ce qui risque d'imputer à Ibn 'Arabī des contrevérités lourdes de conséquences : le ta'wīl comme ésotérisme d'après $\mathrm{H}$. Corbin, le ta'wīl comme méthode philosophique selon Abū Zayd, le ta'wìl en tant que jugement et probabilité chez M. 'Abdelhạq, le ta'wil en tant que doctrine panthéiste selon Dahabī.

Ces résultats ont, certes, leur mobile interne et leur ambition idéologique : lire la mystique musulmane à l'aide des instruments scientifiques et méthodologiques appropriés, élargir le champ de vision et d'investigation dans les études islamologiques, réduire le soufisme à une intrusion doctrinale étrangère à l'islam, etc. Mais ces projets ne nous enseignent pas ce que le texte de notre auteur veut dire dans son expression même. Ce qui nous fait perdre la chance de découvrir Ibn 'Arabī par Ibn 'Arabī lui-même sans que cette découverte soit une redondance ou tautologie.

\section{3- LE TA'WĪL ET SES ORIGINES AMBIVALENTES : L'ARCHÈ ET LE TÉLOS}

La remarque de P. Ricœur, «il n'y a pas d'herméneutique générale, mais des théories opposées concernant les règles de l'interprétation », trouve ici sa pleine justification. En effet, le texte (et en particulier le Coran) suscite la curiosité de nombreuses doctrines qui tentent de cerner sa nature par une approche qui prend plusieurs dénominations : analyser,

\footnotetext{
44. Ibid., p. 341-42.

45. Ibid., p. 350.

46. Ibid., p. 411.
} 
décrire, découvrir, développer, éclaircir, expliquer, exposer, exprimer, interpréter, lire, montrer, saisir, traduire, etc.

Ces techniques d'appréciation ont été occultées par une dichotomie imposante, à la fois doctrinale et politique, qui fait toujours parler d'elle.

Cette dualité se cantonne dans le couple expliquer/interpréter ou bien exégèse/ herméneutique, c'est-à-dire tafsìr et ta'wïl. Elle n'a pas été instaurée dans un consentement mutuel mais a vu le jour dans un processus conflictuel autour de la réalité du texte : qu'estce qui définit cette réalité ? Une simple explication des mots ou bien une interprétation profonde qui va au-delà de leurs frontières littérales?

Cette dualité ne s'est pas fondée sur un terrain neutre mais s'est rapportée à d'autres couples de notions : extérieur (zāhir)/intérieur (bāțin) sur le plan spirituel, sensible (hissì)/ intelligible ( $\left.m a^{\prime} q u \bar{l}\right)$ au niveau philosophique, explicite (muhkam)/équivoque (mutašābih) sur le plan exégétique. Ce dernier couple est le véritable fondateur de la polémique sur la manière d'appréhender le texte coranique.

Le verset de la sourate $\bar{A} l$ 'Imrān y fait mention: "C'est Lui qui a fait descendre sur toi le Livre: il s'y trouve des versets explicites qui sont la base du Livre et d'autres versets équivoques. Les gens qui ont au cœur une inclination vers l'égarement mettent l'accent sur les versets à équivoque cherchant la dissension en essayant de leur trouver une interprétation, alors que nul n'en connaît l'interprétation, à part Dieu. Mais ceux qui sont bien enracinés dans la science disent: "Nous y croyons : tout est de la part de notre Seigneur". Mais seuls les doués d'intelligence s'en rappellent» (Cor. 2/7).

La question du muhkam et du mutašābih est la véritable problématique qui a suscité l'avènement du ta'wīl. La majorité des œuvres exégétiques ont mis sur le tapis de la discussion cette problématique.

Dans son Fahm al-Qur'ān, al-Ḥārit al-Muhāsibī (m. 243/950) évoque les multiples problèmes liés à la compréhension du Coran, notamment ce qui a trait aux couples abrogatif (nāsihn)/abrogé (mansūhn) ${ }^{47}$, explicite/équivoque, etc. Il rapporte la parole d'Ibn 'Abbās, le premier commentateur du Coran, selon laquelle les versets explicites sont abrogatifs et concernent le licite, l'illicite et les œuvres prescrites ${ }^{48}$. Il rapporte d'Ibn 'Abbās aussi la signification eschatologique du mot ta'wīl : «Sa parole "Nul n'en connaît l'interprétation, à part Dieu”, c'est-à-dire le jour de la résurrection qui n'est su que par Dieu ${ }^{49}$. »

Une autre parole rapportée par Muhāsibī consiste à dire que chaque verset a un extérieur (zahr, littéralement un dos) et un intérieur (bațn, littéralement un ventre), une limite (hadd ou le terme, la fin de quelque chose) et un prélude (mațla ou le commencement, le début). Cette parole rejoint en quelque sorte le verset «Il est le Premier et le Dernier et Il est l'Apparent et le Caché » (Cor. 57/3). Muhāsibī commente cette parole en disant

47. « Abrogatif, qualité reconnue à un verset du Coran ou à un hadith qui, dans une perspective historico-juridique, apporte une modification à une règle énoncée par un autre verset ou un autre hadith considéré dès lors comme abrogé » (Dominique et Janine SouRDEL, Dictionnaire historique de l'islam, Paris, PUF, 1996, p. 21).

48. H. Muḥ̄sisī, Fahm al-Qur'ān (La compréhension du Coran), éd. H. Quwwatlī, [s. 1.], éd. Dār al-Fikr, 1971, p. 326

49. Ibid., p. 328 ; v. également ABū 'UBAYD QĀsIm в. SALLĀm, Kitāb al-nāsih wa l-mansūhn (Le livre de l'abrogatif et de l'abrogé), éd. John Burton, Clerk of the Trust, Cambridge, 1987, p. 3. 
que le verset a trois dimensions : l'extérieur est la récitation (tilāwa) ${ }^{50}$, l'intérieur est l'interprétation ( $t a$ 'wìl) et la limite est le seuil de compréhension (muntahā al-fahm).

Que l'intérieur (bātin) soit lié au ta'wīl est l'apanage de nombreux exégètes d'inspiration ésotériste comme on le verra tout à l'heure avec un auteur ismaélien Nu'mān b. Hayyūn al-Tamīmī (m. 363/973), auteur de Asās al-ta'wīl (Le fondement de l'herméneutique). L'explication la plus plausible que Muhāsibī semble retenir est celle de Mālik b. Anas (m. 179/789) à qui on demande si l'interprétation sue uniquement par Dieu est connue également par ceux qui sont enracinés dans la science (rāsihūn fíl-ilm). Il répond que ces initiés disent « Nous y croyons : tout est de la part de notre Seigneur », mais ne savent pas son interprétation ${ }^{51}$. Ces explications associent « les enracinés dans la science » à la foi (« āmannā bihi » dit le verset) et Mālik b. Anas ajoute une autre qualité : la morale ou la pratique spirituelle (al-rāsihūn fì l-'ilm hum al-'āmilūn). Ces analyses nous aident à définir la science comme une qualité inhérente à la foi chez Ibn 'Arabī et non pas comme un attribut issu du ta'wīl ou de l'opinion individuelle (zann, ra'y, etc.).

Les explications données par Muhāsibī sont développées de façon exhaustive dans le magnum opus d'Abū Ǧa'far M. b. Ğarīr al-Ṭabarī (m. 310/923) ${ }^{52}$, Ğāmi' al-bayān 'an ta'wīl āy alQur'ān (La somme de la langue dans l'interprétation du Coran). Si nous référons aux versets où figure le mot ta'wìl, nous trouvons des commentaires différents en fonction du texte et du contexte. Le verset de la sourate Yūsuf « Ainsi ton Seigneur te choisira et t'enseignera l'interprétation des rêves » (Cor.12/6) met déjà l'accent sur ce que le mot ta'wïl veut dire ici : « Ton Seigneur t'apprendra la science de l'aboutissement ( $m \bar{a}$ ya'ul..., littéralement résultat, terme, conséquence, etc.) des paroles de gens sur ce qu'ils voient dans leur sommeil. Ceci signifie l'interprétation du songe (ta'bir al-ru'yā) ${ }^{53}$. "

Tabarī rapporte la signification du ta'wïl comme interprétation des rêves des premiers exégètes Qatāda (m. 118/736) et Muğāhid b. Ǧabr (m. 104/722). Cette interprétation sera nuancée dans l'exégèse mystique, car le songe (manām, hulm, hayāl, etc.) n'a pas la même acception sémantique et spirituelle que le mot ru'yā qui signifie plus qu'un songe. L'autre définition donnée par Țabarī est celle d'Ibn 'Abbās, une définition eschatologique du ta'wīl

\footnotetext{
50. Sur ce point v. Claude GILLIoT, « Les débuts de l'exégèse coranique », REMMM, 1990/58-4, p. 92 : « On peut donc représenter la première étape de l'exégèse comme paraphrastique, liée qu'elle était à la récitation du Coran, le lecteur s'arrêtant sur quelques termes ou expressions qui faisaient problème, sans grand souci d'une "exégèse textuelle", c'est-à-dire qui fît référence à d'autres passages du Coran ou à son analyse narrative. » Les trois dimensions sont mentionnées par IBN “ARABİ dans la Risālat al-anwār ("Traité des lumières », in Rasā'il, Hayderabad, 1948, 19 p.), une épître sur le cheminement initiatique qui commence par l'aspect extérieur (récitation = tilāwa, invocation = dikr, etc.) et finit par la saisie intuitive et contemplative des réalités supérieures en passant par la modalité du dévoilement (kašf) qui correspond à l'interprétation ( $\left.t a^{\prime} w i ̄ l\right)$.
}

51. Н.. Мuب̣Āsıīi, op. cit., p. 330.

52. Sur cet exégète v. Cl. GiLlıт, Exégèse, langue et théologie en islam. L'exégèse coranique de Tabarī, Paris, Vrin (« Études musulmanes », 32), 1990.

53. ȚABARĪ, Ğāmi al-bayān, Le Caire, $3^{e}$ éd., 1968, t. 12, p. 153. 
" "Nul n'en connaît l'interprétation à part Dieu”, c'est-à-dire interprétation (littéralement son destin, son terme) le jour de la résurrection que Dieu ${ }^{54}$. »

Tabarī se réfère aussi aux conséquences ('awāqib) ou bien aux prolongements d'une affaire comme le problème de l'abrogatif et de l'abrogé, c'est-à-dire que Dieu seul sait quand et où un verset abrogatif allait descendre pour instaurer une nouvelle règle. Paul Nwyia dit: «Dans d'autres textes, tandis que R. Blachère traduit ta'wïl par "explication" ou "supputation", Muqātil le traduit par 'āqiba, conséquence. Ta'wīl signifie alors, non pas l'interprétation de l'événement futur, mais cet événement futur lui-même en tant que conséquence ou aboutissement de l'action actuelle ou passée ${ }^{55}$. »

Sur "les enracinés dans la science ", Țabarī adopte la même signification établie par ses prédécesseurs, à savoir que ces initiés ignorent tout sur l'interprétation exacte des versets et sur le jour de la résurrection. Leur seul credo est d'adhérer à ces préceptes fixés par la Loi ${ }^{56}$. Ces initiés sont enracinés dans la foi comme ils sont qualifiés par la science.

Outre les significations oniriques et eschatologiques, Tabarī met en exergue la signification étymologique qui comporte une certaine équivocité : «Quant au sens du ta'wil dans le langage des Arabes c'est l'explication (tafsir), la référence (marğa', littéralement le retour) et la destinée (mașir) ${ }^{57}$. » L'aspect amphibologique du ta'wīl apparaît dans le double sens de ce mot, deux significations de surcroît contradictoires : la source ou l'origine et le terme ou la destinée.

À vrai dire, ce double sens a une conséquence symbolique d'une grande importance : le ta'wīl est pris dans son aspect cyclique (d'où "le cercle herméneutique" chez les herméneutes des $17^{\mathrm{e}}$ et $18^{\mathrm{e}}$ siècles, notamment chez Flacius, Dannhauer, Rambach, Chladenius, etc., c'està-dire comprendre les Écritures saintes en fonction du tout (le Livre) et comprendre ce dernier à la lumière de celles-là ${ }^{58}$ ).

Le ta'wïl comme dimension cyclique ${ }^{59}$ (l'origine (archè) rejoint la fin (télos) comme dans un cercle) qui réunit la cosmogonie et l'eschatologie est le propre d'une interprétation ésotérique donnant le primat au bāțin et à la dimension tragique et pathétique de la destinée.

Cette scénographie mêle drame, ascension et homélie. Elle postule une hiéro-histoire, l'histoire sacrée d'un fatum. Les germes de cette interprétation ésotériste se trouvent chez Nu'mān b. H. Tamīmī qui entreprend dans Asās al-ta'wīl d'expliquer les récits des prophètes (qașaș al-anbiyā'). Ceci nous rappelle dans une certaine mesure et sur un autre plan le Fuṣūs

54. Ibid., t. 3, p. 181 et aussi 182 sur la date de la fin du monde (qiyām al-sāa $a$ ) défiant tout pronostic ou divination (kahāna).

55. P. NwyIA, Exégèse coranique et langage mystique, Beyrouth, Dār al-mašriq, 1970, p. 60.

56. ȚABARĨ, op. cit., t. 3, p. 183-184.

57. Ibid., p. 184.

58. Sur le cercle herméneutique, cf. GADAMER, Vérité et méthode, op. cit., p. 286 sq.

59. D’où le titre de H. CorBin, Temps cyclique et gnose ismaélienne, Paris, Berg international, 1982. 
d'Ibn 'Arabī. Le souci de Nu'mān est d'établir l'institution du ta'wīl et sa légitimité en se référant aux textes de la tradition (en particulier le Coran).

Les termes récurrents sont l'extérieur (zāhir) et l'intérieur (bāṭin) comme il l'explique dans l'introduction de l'ouvrage ${ }^{60}$. Mais ce qui est important et souvent négligé, c'est que la théorie du ta'wïl est fondée sur la notion du mitāl qui comporte, à son tour, des significations ambivalentes ${ }^{61}$ : la racine $M-\underline{T}$ - $L$ recèle de multiples acceptions :

1- Matal signifie semblable, similaire, pareil, ressemblant, allégorie, exemple, parabole, etc.

2- Mițāl signifie type, modèle, archétype, image, symbole, idée, etc.

3- Tamtîl veut dire comparaison, analogie, représentation, etc.

4- Mutūul est présence, comparution, apparition, etc.

Certains versets y font mention: "Dieu ne se gène point de citer un exemple quel qu'il soit: un moustique ou quoi que ce soit au-dessous; quant aux croyants, ils savent bien qu'il s'agit de la vérité venant de la part de leur Seigneur; quant aux infidèles, ils se demandent "Qu'a voulu dire Dieu par un tel exemple?" » (Cor. 2/26) ; "Nous avons dans ce Coran cité pour les gens des exemples de toutes sortes afin qu'ils se souviennent » (Cor. 39/27) ; «Telles sont les paraboles que Nous citons aux gens ; cependant, seuls les savants les comprennent » (Cor. 29/43). En tout le nombre des versets qui comportent la racine $M-\underline{T}$ - $L$ est de 169.

La théorie du mițl/mițāl a été surtout approfondie par Abū Hāāmid al-Ġazālī (m.505/1111) et nous aurons l'occasion d'en signaler l'importance et l'influence sur le soufisme tardif dont la doctrine d'Ibn 'Arabī.

Nu'mān prend le ta'wīl et le mitâal dans un sens analogue. Ce dernier est employé pour symboliser quelque chose, c'est-à-dire que sa présence réelle ou virtuelle implique nécessairement une chose. En d'autres termes, le mitāl est inséparable de la chose qu'il désigne comme l'analogie entre la balance et la justice. Nu'mān recense certains symboles indissociables des prophètes : Noé et l'Arche, Abraham et la Ka'ba, Moïse et le Bâton, Jésus et la Croix, Muhammad (Mahomet) et la šahāda (profession de foi) ${ }^{62}$.

En réalité, ce n'est pas tant les correspondances symboliques qui posent problème que les versets et les traditions à caractère anthropomorphique, c'est-à-dire attribuer à

60. Tамі̄mī, Asās al-ta’'wīl, éd. 'Ārif Tāmir, Beyrouth, éd. Dār al-țaqāfa, [s. d.], p. 28-32.

61. Sur cette notion et les niveaux d'interprétation chez les exégètes v. ABŪ ZAYD, N. H., al-Ittiḡāh al-'aqlīfĩal-tafsīr (Le courant rationaliste dans l'exégèse), Beyrouth-Casablanca, éd. Markaz, 3e éd., 1996, p. 93-97 et p. 141-239.

62. TAMі̄MĪ, op. cit., p. 33 
Dieu des membres et des états humains. Ces considérations théologiques seront discutées à propos de l'herméneutique d'Ibn 'Arabīi ${ }^{63}$.

\section{4- L'INTERPRÉTATION SYMBOLIQUE DANS LE SOUFISME : QUELQUES REPÈRES MÉTHODOLOGIQUES}

Le thème du ta'wìl dans le soufisme est une mine inépuisable. P. Nwyia en a retracé le fondement et l'évolution sous le double aspect diachronique (l'histoire du mot et son devenir) et synchronique (les multiples significations du mot dans un système donné, ici l'expérience mystique).

Ce qu'il faut retenir de cette étude riche et bien documentée est la question du sens pluriel ou bien les multiples aspects ou facettes d'un mot (wuğūh) que P. Nwyia découvre chez Muqātil b. Sulaymān (m. 150/767) ${ }^{64}:$ « Si cette exégèse primitive dont Muqātil est le témoin, n'est pas mystique, elle est loin d'être purement littéraliste. Nous montrerons qu'elle est largement ouverte au travail de l'imagination, accueillant en son sein des éléments allégoriques ou mythiques qui préparent les développements ultérieurs de l'exégèse. Par la méthode des wuğūh, Muqātil découvre dans le Coran une pluralité de sens qui porte en elle les possibilités de multiples lectures du Coran. L'herméneutique prend naissance quand un texte se révèle porteur d'un sens autre que le sens apparent ou littéral ${ }^{65}$. Cette méthode exégétique offre uniquement le cadre formel à une interprétation soufie. Le contenu de celle-ci est à chercher du côté de l'expérience mystique elle-même.

De par sa nature ineffable, cette expérience se heurte à des obstacles de communication : «Il ressort ainsi de cette page très dense de Kalābād̄i que le langage technique des soufis est né d'une nécessité inhérente à la nature de l'expérience mystique qui ne peut être communiquée à une communauté de croyants polyvalente sans engendrer des malentendus qui mènent tôt ou tard à des conflits de doctrine ${ }^{66}$.

Contrairement à ceux qui réduisent cette expérience à un élément extrinsèque (hermétisme, manichéisme, néoplatonisme), P. Nwyia démontre avec vigueur la source endogène où cette expérience puise ses racines: "C'est donc dans le Coran que prend naissance le langage de l'expérience mystique musulmane, et, aussi technique qu'il soit ou qu'il le devienne, ce langage devra d'une manière ou d'une autre faire la preuve de son origine coranique, sinon quant à sa forme, du moins dans son contenu ${ }^{67}$. "

L'idée de P. Nwyia va à l'encontre de celle de R. Blachère qui opte pour une interprétation symbolique vidant le texte coranique de son sens précis. Dans le sillage des docteurs de la Loi (fuqaha'), il va jusqu'à accuser l'interprétation soufie de déformer et pervertir le texte révélé. Ce contresens méthodologique ne cesse d'alimenter les exégèses hostiles à l'interprétation mystique sous prétexte que la forme et le contenu de cette expérience se

63. En ce qui concerne l'anthropomorphisme (tašbīh) dans la pensée théologique v. Cl. Giluıot, « Muqātil, grand exégète, traditionniste et théologien maudit », Journal asiatique, 1991/1-2, p. 39-92 ; chez Ibn 'Arabī v. M. CHodкIEWICz, Un Océan sans rivage. Ibn 'Arabī, le Livre et la Loi, Paris, Seuil, 1992 ("Librairie du XX siècle »).

64. Sur les trois sens : littéral, historique et allégorique, v. P. Nwiya, op. cit., p. 25-108 et 209.

65. P. NWYIA, op. cit., p. 9-10.

66. Ibid., p. 21.

67. Ibid., p. 22. 
trouvent ailleurs, dans les doctrines philosophiques et métaphysiques étrangères à l'esprit coranique originel : « Le commentaire soufi du Coran se fonde avant tout, nous l'avons dit, sur la réalisation spirituelle. C'est-à-dire qu'il se situe sur un plan qui lui est propre, qui n'est en tout cas ni celui de l'exégèse littéraliste ni celui de la réflexion théologique. Quelle que soit la position de celui qui étudie ce genre de commentaire, quel que soit le degré d'arbitraire ou d'imagination qu'il croit y déceler, nous pensons que cette exégèse doit être abordée en tenant compte de la conception que les soufis eux-mêmes en ont, en admettant a priori que cette appréhension du texte sacré est issue d'une expérience qu'ils sont seuls à avoir vécue ; faute de quoi on ne peut que s'exposer à de graves contresens ${ }^{68}$. »

Pour comprendre le commentaire mystique, il est donc préférable de le situer dans son propre champ sémantique, historique et théologique. La seule différence qui caractérise un commentaire est les multiples perceptions qui se rapportent à lui.

Pour cela, P. Nwyia recense trois orientations de l'exégèse musulmane :

1- L'exégèse sunnite qui met en valeur le tafsīr, c'est-à-dire l'explication du texte (šarh) au niveau des mots (alfāz) et en fonction de la discipline : grammaire, histoire, théologie, jurisprudence, etc.

2- L'exégèse chiite qui se rapporte au ta'wìl, c'est-à-dire l'interprétation au niveau du sens ésotérique. Ce sens caché est du ressort de l'imam, investi pour une mission de décryptage pour déceler une vérité profonde. Les implications apologétiques et sociopolitiques de cette mission sont évidentes.

3- L'exégèse soufie qui emploie la méthode de l'istinbāt qu'on pourrait traduire par "élucidation" (P. Lory ${ }^{69}$ ) ou déduction : «En fait quand les soufis eux-mêmes parlent de leur méthode, ils ne l'appellent ni tafsìr ni ta'wīl, mais istinbāt : mot d'origine coranique, préféré par eux pour mieux se distinguer des autres. Littéralement, istinbāt désigne l'acte de faire jaillir l'eau d'une source : c'est donc faire venir à la surface ce qui était caché au fond de la terre. Pour les soufis, le texte coranique a un fond, un bāțin caché dans son zāhir, son extérieur, il a un sens intime et spirituel caché au-delà de son sens littéral, et c'est ce sens que révèle l'istinbăț ${ }^{70}$. »

Al-Sarrāğ al-Ṭūsī (m. 378/988) consacre plusieurs pages à l'istinbāṭ dans son ouvrage alLuma. Il explique la structure et la fonction de cette notion qui se distingue du syllogisme. Ce dernier est un raisonnement logique qui consiste à tirer d'une ou plusieurs propositions données une autre proposition qui en est la conséquence nécessaire. Cette déduction est un passage de l'implicite à l'explicite.

L'istinbāt d'après Sarrāğ a pour moyen de réalisation la méditation et la présence du cœur (hudūur al-qalb) pour comprendre le texte ${ }^{71}$. Il rapporte d'Abū Sa'īd al-Harrāz (m. 289/899) que la compréhension du texte coranique (fahm) signifie agir en fonction de ses préceptes. Il contient la science, la compréhension et l'istinbāt . Ce dernier serait donc non

68. Pierre LoRY, Les commentaires ésotériques du Coran d'après 'Abd al-Razzāq al-Qāšān̄i, Paris, Les Deux Océans, 1980, $2^{e}$ éd., p. 17-18.

69. Ibid., p. 13.

70. P. NWYIA, op. cit., p. 34.

71. Sarrāğ, Luma', Le Caire, 1960, p. 106-107. 
seulement une compréhension intellectuelle ou intuitive du texte mais aussi la mise en application de ses vérités intrinsèques.

Cette subtilitas applicandi est manifestement appréciée par 'Abd al-Razzāq al-Qāšānī (m. 730/1329) qui découvre un aspect particulier du ta'wïl consistant à appliquer le symbolisme coranique au niveau microcosmique : « Le tațbiq (= application) est un mode possible du ta'wìl qui se distingue, non par la nature du sens extérieur du verset auquel il se rapporte, mais uniquement par son domaine d'application qui est celui de la "psychologie spirituelle ${ }^{72}$." "

Cette herméneutique appliquée a été adoptée de nos jours par 'Allāl al-Fāsī dans un ouvrage relatant l'histoire de l'exégèse de façon claire et didactique ${ }^{73}$. Si nous nous contenterons de l'exégèse soufie, les œuvres de 'Abd al-Raḥmān al-Sulamī (m. 410/1021) Haqā’iq al-tafsìr (Les réalités de l'exégèse) et de 'Abd al-Karīm al-Qušayrī (m. 465/1072) Lațā'if al-išārāt (Les subtilités des allusions symboliques) sont dans ce contexte influentes. Le commentaire de Qušayrī du verset (Cor. 2/7) inclut plusieurs éléments exégétiques établis par ses prédécesseurs: le zāhir représente l'aspect évident du texte (tanzīl) et le bāțin symbolise le secret intime (sirr) qui doit être préservé et non divulgué. Les initiés " enracinés dans la science » (rāsihūn fì l-‘ilm) perçoivent le sens du texte conformément aux fondements spirituels : « La voie des gens de l'allusion (išāra) et de la compréhension ( fahm) est de prêter oreille en ayant le cœur présent. Ainsi, ils établissent les allusions issues du dévoilement intuitif en fonction des termes qui apparaissent à leur entendement ${ }^{74}$. »

Qušayrī pense que le zāhir est expliqué par l'expression ('ibāra) alors que le secret (sirr) est communiquée par l'allusion (išära), ce qui évite les malentendus et les agressions provenant des savants traditionnistes. Le couple expression/allusion est une autre traduction doctrinale de la dualité extérieur/intérieur qui comprend la dimension symbolique des vérités enfouies dans le Coran: "Certes, dans ce langage mystique, il y a la 'ibāra et la išāra, le langage expressif et clair et le langage allusif qui suggère les choses sans les dire [...]. En effet, le langage allusif n'est pas, chez eux, un langage incohérent et incontrôlé ; c'est le langage se haussant au niveau du symbole et devenant, seulement à cause de cela, ésotérique, puisqu'un symbole ne parle qu'à celui qui sait l'interroger. Quant à la "ibāra, le langage qui fait "passer" le dedans au dehors et qui "exprime" ce qui est

72. LORY, P., op. cit., p. 37.

73. 'A. Fāsī, al-Madhal li 'ulūm al-Qur'ān wa al-tafsīr (Introduction aux sciences du Coran et de l'exégèse), Casablanca, Mațba'at al-Dār al-Bayḍā', 1988, p. 85 et 91.

74. Qušayrī, Lațā’if al-išārāt, Le Caire, éd. al-Hay’a al-mișriyya, 1981², I, p. 220. 
expérimenté, son originalité prouve la nouveauté de l'expérience qui a été à l'origine de son invention ${ }^{75}$. »

Le couple expression/allusion renvoie donc à deux sortes de ta'wïl :

1- L'herméneutique spéculative (ta'wīl 'aqlī) qui favorise l'opinion et l'étude grammaticale, historique et rhétorique du texte coranique comme c'est le cas chez les mu'tazilites.

2- L'herméneutique illuminative ( $t a$ wìl kašfī) est la voie du dévoilement qui saisit directement et intuitivement la signification du texte ${ }^{76}$. Ce mode exégétique est adopté par l'ensemble des commentaires soufis.

D'autres mystiques, comme Ġazālī, ont acquiescé aux deux orientations herméneutiques (spéculative et intuitive). La référence à Ġazālī est capitale, car il représente le croisement du soufisme et de la philosophie. Il a laissé une empreinte doctrinale visible chez la plupart de ses successeurs dont Ibn 'Arabī. Son érudition est perceptible dans une majeure partie de son œuvre monumentale. Le ta'wil y prend une place importante, notamment dans les épîtres qu'il a composées comme Ğawāhir al-Qur'ān (Les joyaux du Coran), Qānūn al-ta'wīl (Le canon de l'herméneutique) et Faysal al-tafriqa bayna al-islām wa al-zandaqa (La distinction entre l'islam et l'athéisme).

L'idée principale de Ġazālī est qu'il existe un “canon” pour l'herméneutique et, en particulier, des règles précises pour l'interprétation du Coran. Ce dernier ne peut être interprété de n'importe quelle façon. Allusion faite aux ésotéristes auxquels il a consacré une véhémente polémique : "Tout ce qui a été rapporté dans l'aspect extérieur (zāhir) des œuvres prescrites, de la résurrection et des choses divines (= théologie) sont [d'après eux] des symboles de leur aspect ésotérique ${ }^{77}$. "

Dans sa réponse aux interprétations ésotéristes, Ġazālī a compris que le zāhir n'est qu'un alibi et que leur intention est d'abroger la signification littérale et la substituer par des symboles. Ainsi, les mots deviennent comme des récipients aptes à contenir toute substance, c'est-à-dire toute interprétation cautionnant leur vision du monde. Faisant face à cette orientation présomptueuse, Ġazālī déclare: "Nous avons une norme de l'interprétation (mi'yār fí al-ta'wīl) qui consiste à dire que si la vision spéculative prouve la vanité de l'aspect apparent d'un mot, nous savons par évidence que le sens voulu est autre chose, à condition que le mot lui corresponde ${ }^{78}$ par le biais de la métaphore ${ }^{79}$. $"$

Conscient des tentations que provoquent l'interprétation du texte sacré et les dérives éventuelles, Ġazālī instaure donc certaines règles herméneutiques inhérentes au Livre. Il tente aussi de comprendre le conflit des interprétations auquel se livrent les multiples schismes dans l'islam. Telles sont, par exemple, les questions qu'il se pose dans le Faysal

75. P. NWYIA, op. cit., p. 6.

76. Sur ces deux orientations herméneutiques v. P. LORY, op. cit., p. 12-17.

77. ĠAzĀLĪ, Faḍa'ị al-Bāṭiniyya (Les scandales des ésotéristes), éd. critique 'A. Badawī, Le Caire, éd. Dār al-qawmiyya, 1964 , p. 55.

78. C'est-à-dire qu'il correspond au sens voulu par l'auteur (mens auctoris) en ayant à la fois un sens propre et un sens figuré.

79. ĠAZ̄̄LĪ, op. cit., p. 53. 
al-tafriqa afin de cerner les abus d'excommunication (takfir) émanant de chaque école théologique. L'originalité de Ġazālī dans ce livre est d'instaurer le ta'wīl sur des bases cognitives, c'est-à-dire sur ce qu'on pourrait appeler communément « la théorie de la connaissance ${ }^{80} »$.

Pour interpréter la tradition, il faut croire à l'existence de réalités physiques et métaphysiques rapportées par des récits (ahbār).

L'existence (wuğ $\bar{u} d$ ), selon Ġazālī, se divise en cinq niveaux ${ }^{81}$ :

1- L'existence essentielle (wuğūd dāatî) indépendante du sensible et de l'intelligible. Elle n'a pas besoin d'interprétation, car les choses existent par elles-mêmes indépendamment de toute perception. La référence scripturaire (dans le Coran et les traditions prophétiques) est l'existence de sept cieux, du Piédestal, du Trône, etc.

2- L'existence sensible (wuğūd hissī) est tout ce qui est donné à la vision et n'a pas d'existence extérieure, comme toute image spectrale. Ainsi par exemple, l'apparition de l'Ange Gabriel au Prophète dans l'image de Dihya al-Kalbī, ou le verset qui dit « Nous lui envoyâmes Notre Esprit (Gabriel), qui se présenta à elle ( $f a$ tamattala lahā) sous la forme d'un homme parfait » (Cor. 19/17). Ce que la personne perçoit est le modèle imagé (mitâal) de la chose. Ce modèle est vu oculairement par les prophètes dans la veille (yaqaza) et vu imaginalement par le commun des gens dans le songe (manām) ${ }^{82}$. La référence dans la tradition est le hadith selon lequel le jour de la résurrection, la mort apparaît sous la forme d'un bélier qui est égorgé entre le paradis et l'enfer ${ }^{83}$.

Ǵazālī explique que ce récit est purement image, car la forme représentative de la mort apparaît aux yeux des gens et n'a pas d'existence réelle ${ }^{84}$. D'où la nécessité du ta'wīl qui reconduit le sens à son origine étymologique et donne crédit au récit du Prophète en admettant sa véracité.

3- L'existence imaginale (wuğ $\bar{u} d$ hayāalì) est tout ce qui apparaît dans l'imagination du percevant comme formes détachées de la matière. Ġazālī rapporte le cas du Prophète qui voit Jonas dans deux pèlerines invoquant avec les monts les louanges de Dieu. Il explique que c'est l'image de Jonas que le Prophète a contemplé. La contemplation signifie ici voir oculairement ce qui apparaît imaginalement.

4- L'existence intelligible (wuğūd 'aqlī) qui consiste à saisir la signification ( $m a$ 'n $\bar{a})$ d'une chose, en lui attribuant une fonction déterminée. Exemple de la main (yadd) qui signifie la force (bațš), ou de la plume (qalam) qui désigne la transcription des sciences. La référence textuelle que Ġazālī mentionne est le hadith « Dieu a fait fermenter par Sa main l'argile d'Adam durant quarante jours ${ }^{85}$ ». La main de Dieu a ici une signification intelligible qui

80. Nous avons tenté une étude sur la connaissance chez Ġazālī, « L'apport de Ġazālì aux fondements mystiques et philosophiques de la connaissance et l'objection d'Ibn 'Arabī à la question de la vision de Dieu », Studia Islamica, 2004/98-99, p. 131-156, Paris, Maisonneuve et Larose.

81. ĠAZĀLĪ, Faysal al-tafriqa, éd. Sulaymān Dunyā, Le Caire, 1961, p. 176-178.

82. ĠAz̄̄Lī, Qānūn al-ta’wīl, éd. Mahmūd Bīğū, Damas, éd. al-Mațba‘a al-'ilmiyya, 1993, p. 28.

83. BuH̄̄̄RI, Șaḥiḥ (Les traditions prophétiques authentiques), IV, p. 117-118, nº $4730 ;$ Muslim, IV, p. 2188, nº 2849.

84. ĠAZĀLī, Qānūn al-ta'wìl, p. 22 ; Faysal al-tafriqa, p. 179.

85. 'IRĀQII, Tahrī̌̆ al-Ihyyà', IV, p. 277. 
n'est ni la forme sensible (ou anatomique) ni l'image représentée. Elle désigne les attributs divins de force (baț̌s), de don ('atā') et de privation $\left(\operatorname{man}^{\natural}\right)$ : « La première chose que Dieu a créée est l'Intellect ('Aql) et a dit : c'est par toi que Je donne et Je prive ${ }^{86}$. »

L'Intellect, signifié dans ce hadith par l'Ange, est ce qui saisit les choses par sa substance séraphique. Il est aussi le Calame qui inscrit les sciences et les sagesses dans le cœur des prophètes et des saints par un mode intuitif qui est l'inspiration (ilhām) et le dévoilement (kašf) : "La première chose que Dieu a créé est le Calame ${ }^{87}$. " Somme toute, l'aspect intelligible des choses permet d'interpréter le texte révélé de façon adéquate sans recours aux tendances anthropomorphistes.

5- L'existence assimilable (wuğūd šabahī) est l'existence d'une chose similaire à une autre qui n'existe pas dans le sensible, l'imaginal ou l'intelligible. Cette existence reconnaît l'aspect anthropomorphique des attributs divins comme la joie, la colère, la patience, etc.

Ces cinq modalités d'existence sont aussi des modes d'interprétation appréciés différemment par les écoles théologiques. Elles se présentent de façon superposée. A défaut d'un argument tangible (burhān) qui peut étayer le mode essentiel, l'interprétation sensible s'avère nécessaire. Si celle-ci n'est pas de mise, l'imaginal ou l'intelligible prennent alors le relais. Ġazālī remarque cependant que l'usage non approprié de l'une des interprétations peut susciter des malentendus.

Pour prévenir contre ces dérives que les théologiens s'attribuent mutuellement sous forme d'incrimination (égarement, dalāl et hérésie, bid'a), il instaure une règle herméneutique pour deux catégories de gens :

1- Les croyants qui doivent suivre à la lettre les dits de la tradition. Son livre Ilğāam al'awāmm 'an 'ilm al-kalām (Interdire à la masse l'étude de la théologie, Le Caire, 1933) leur est destiné.

2- Les hommes de la spéculation (nuzzāor) parmi les théologiens qui ont des points de vue divergents. Il leur a consacré plusieurs essais comme al-Iqtișād fi al-itiqād (Abrégé de la doctrine religieuse, éd. Ibrahim A. Çubukçu et Huseyin Atay, Ankara, 1962), al-Mustașfā min 'ilm al-ușūl (Le meilleur des fondements de la jurisprudence, éd. Bulaq, 2 vol., 1322h) et al-Qistās al-mustaqìm (La balance droite, éd. Victor Chelhot, Beyrouth, 1983).

Il attribue ces divergences à des différences d'opinions, de sources de renseignements, de tempéraments, des confusions sur la signification des mots, etc. La règle herméneutique pour les croyants est la foi (ìmān) et celle des hommes de la spéculation est la certitude (yaqīn) et l'argument tangible (burhān).

Disons que le canon herméneutique prend chez Ġazālī deux significations: une signification morale et théologique sur les usages de l'argumentation et les risques que provoque l'opinion personnelle ( $\left.r a^{\prime} y\right)$ dépourvue d'assises scripturaires; et une signification philosophique et mystique sur la nature des versets équivoques ou à caractère anthropomorphique. Cette deuxième signification a fait l'objet d'une analyse consistante dans plusieurs de ses épîtres comme al-Maḍūn bihi 'alā gayr ahlih, Ğawāhir al-Qur'ān et

86. SuYūTī, al-Ǧāmi al-kabīr, II, p. 126.

87. IBn Hanbal, Musnad, V, p. 317. 
Miškāt al-anwār (Le tabernacle des lumières) dans son commentaire du verset de la lumière (Cor. 24/35).

Dans le Miškāt il écrit : « La Miséricorde divine a fait qu'il y ait une relation d'homologie entre le monde visible et celui du Royaume céleste. En conséquence, il n'y a aucune chose du premier qui ne soit un symbole (mitāll) de quelque chose du second [...]. Une chose est le symbole d'une autre si elle la représente en vertu d'une certaine similitude et si elle lui correspond en vertu d'une certaine corrélation ${ }^{88}$. » Dans le Maḍūn il explique la différence entre le mițl qui est le semblable ou l'identique, et le mițāl qui désigne le modèle, le symbole ou l'exemple. Il applique cette distinction sur les versets ou les hadiths qui comportent ces homologies comme la parole prophétique «Celui qui me voit dans le sommeil me voit réellement, car Satan n'apparaît pas selon mon image (lā yatamattalu bī) ${ }^{89}{ }^{\prime}$.

Cette explication renvoie à l'existence sensible précédemment citée et nécessite un ta'wīl imagé. Par exemple, l'intellect ('aql) est comparé au soleil mais il est différent de ce dernier aussi bien dans le sens que dans la réalité. Leur ressemblance est purement symbolique : l'intellect illumine les formes intelligibles en les rendant claires et accessibles comme le soleil qui illumine les corps sensibles en leur procurant visibilité et distinction.

Les symboles coraniques et prophétiques comme le lait et la corde sont interprétés autrement. Le lait et la corde "symbolisent" respectivement la science et la religion, mais ils "ne sont pas" la science ni la religion : "Le symbole (mitâl) explique la chose et le semblable (mitl) ressemble à la chose ${ }^{90} »(n s)$. Le symbole a une valeur herméneutique et heuristique alors que le semblable se fait passer pour la chose qu'il désigne. Certains aspects de ce symbolisme sont encore exposés de façon claire dans le Ğawāhir al-Qur'ān.

Ġazālī revient ici sur la question du symbole et de la métaphore en disant que chaque chose du monde inférieur est un mițāl du monde supérieur ${ }^{91}$. On a voulu rapprocher l'idée de Ġazālī de celle de Platon qui croit à un archétype idéal et immuable : «Ce texte montre que Gazālī veut dire que les choses dans le monde ont des archétypes ou des symboles dans le monde céleste ${ }^{92} \gg(n s)$.

Or Ġazālī dit tout à fait le contraire, c'est-à-dire que les choses du monde matériel sont des modèles des formes intelligibles. Les choses mentionnées dans le texte coranique ou prophétique comme le doigt, la main, le calame, le visage, le tabernacle, le verre, la lampe, etc. sont à prendre comme des symboles désignant des formes intelligibles ou des qualités morales comme par exemple le verset «Il a fait descendre une eau du ciel à laquelle des vallées servent de lit, selon leur grandeur. Le flot débordé a charrié une écume flottante; et semblable à celle-ci est l'écume provenant de ce qu'on porte à fusion, dans le feu pour fabriquer des bijoux et des ustensiles [...]. Ainsi, Dieu propose des paraboles » (Cor.

88. ĠAZĀLĪ, Miškāt al-anwār, p. 205, in Rasā̉il, Le Caire, [s. d.] ; Le Tabernacle des lumières, trad. R. Deladrière, Paris, seuil, 1981, p. 65-66.

89. BuHĀRī, Șahịh, I, p. 38, n6984 ; Muslim, IV, p. 1775-1776, nº 2266 et 2267.

90. ĠAZĀLĪ, Madnūn, p. 305, in Rasā'il, op. cit.

91. ĠAz̄̄̄İ, Ǧawāhir al-Qur'ān, éd. critique M. Qubbānī, Beyrouth, éd. Dār ihyā' al-‘ulūm, 3e éd., 1990, p. 48.

92. 'Āmir NAĞĞĀR, Naz̧arāt fi fikr al-Ǵazālì (Aperçus de la pensée de Ġazālī), Le Caire, éd. Șafā', 1989, p. 55. 
13/17). L'eau symbolise la science, les cœurs sont les vallées et l'écume flottante représente l'égarement.

Ġazālīintroduit iciune métaphore pour distinguer le tafsìr du ta'wìl.Ce dernier estcomme la pulpe (le fond des choses) masquée par une écorce qui représente l'explication littérale des mots (tafsir ). C'est en allant au fond des termes et en pénétrant l'existence imaginale qu'on pourra découvrir la face cachée des symboles : « Tout ce que ta compréhension peut contenir, le Coran te l'inspire à tel point que si tu lis pendant le rêve sur la Tablette gardée (al-Lawh al-mahfüz), tout ce que tu vois se présente à toi dans un symbole approprié qui nécessite l'interprétation (ta'bir). Sache que le ta'wïl passe par la voie de l'interprétation des rêves. C'est pourquoi nous avons dit que l'exégète (mufassir) tourne autour de l'écorce. Car celui qui traduit le sens de l'anneau, de l'intimité des femmes et des bouches n'est pas comme celui qui perçoit l'appel à la prière avant l'aube ${ }^{93-94}$ ».

Le songe qui fait voir la réalité des choses derrière l'écran des symboles n'est pas un état humain particulier, mais un mode d'être qui s'éclaircit ou se dévoile avec la mort d'après le hadith précédemment cité ${ }^{95}$. Ce dévoilement fait connaître aux gens que les symboles ne sont que des écorces et des coques sur la réalité essentielle des choses.

Le dévoilement prend dans ce contexte le sens du ta'wïl dans la mesure où ce dernier serait l'annonce de la vérité dans le jugement dernier et la réalisation du châtiment ou de la récompense : «Attendent-ils uniquement sa réalisation ( $t a$ ’wīlah) ? Le jour où sa réalisation viendra, ceux qui auparavant l'oubliaient diront: "Les messagers de notre Seigneur sont venus avec la vérité. $Y$ a-t-il pour nous des intercesseurs qui puissent intercéder en notre faveur? Ou pourrons-nous être renvoyés [sur terre], afin que nous œuvrions autrement que ce que nous faisions auparavant?" »(Cor. 7/53). D'après Gazālī, le monde d'ici-bas est celui des songes où les choses apparaissent sous forme de symboles. Mais dans l'au-delà, l'homme atteint le noyau des choses en découvrant leur réalité véritable.

5- LE SYMBOLISME DE LA SCIENCE ET DE LA CONNAISSANCE CHEZ IBN 'ARABĪ: PROCÉDÉ HERMÉNEUTIQUE

L'apport de Ġazālī à l'herméneutique soufie a influencé sans doute les discussions doctrinales jusqu'à Ibn 'Arabī. Même si l'auteur de l'Ihyā' n'a pas fondé une théorie du ta'wīl au sens d'une exégèse coranique vaste et cohérente, sa contribution pour l'instauration d'un canon pour l'interprétation est inestimable. Signalons en particulier le rapprochement entre la dimension cognitive (márifa) basée sur la perception (idrāk) quelle que soit sa nature (sensible, intelligible, imaginale, etc.) et la sphère herméneutique.

La proximité entre l'épistémologie et l'interprétation a été enrichie plus tard par notre auteur explorant davantage cette problématique dans un contexte plus large. Les approches contemporaines de l'herméneutique d'Ibn 'Arabī que nous avons examinées

93. Il dit dans le Miškāt: «Quand quelqu'un se voit en songe portant à la main un anneau avec lequel il scelle la bouche des hommes et l'intimité des femmes, cela signifie que c'est un muezzin qui fait l'appel à la prière du matin pendant le Ramadan» (p. 207 ; trad. p. 68).

94. ĠAZĀLĪ, Ğawāhir, p. 52.

95. Cf. note 32. 
au début de cette étude ne sont pas satisfaisantes pour la simple raison que le vocable "herméneutique" a été trop substantivé alors qu'il s'agit, selon notre lecture d'Ibn 'Arabī, d'un "adjectif".

En donnant à l'herméneutique la forme d'un épithète, nous prétendons ainsi à une prudence méthodologique afin d'éviter les conclusions hâtives qui finissent par tomber dans un contresens comme l'application in situ de la wahdat al-wuğūd. Où et comment Ibn 'Arabī emploie la notion de ta'wīl ? L'œuvre maîtresse reste sans doute les Futūhāâtal-Makkiyya (Les illuminations de La Mecque, Beyrouth, Dār Sādir, [s. d.], abrégées Fut.). D’autres essais comme le Fuṣūṣ al-ḥikam (Les chatons des sagesses, éd. Abū l-'Alā 'Afīfī, éd. Zahra, 1992, abrégées Fuṣ.) et les épîtres rassemblées sous le titre Rasā’il Ibn 'Arabī sont d'une grande importance doctrinale.

Le mot ta'wīl est employé par Ibn 'Arabī avec une extrême précaution. Dans son commentaire du verset « C'est Lui qui vous donne forme dans les matrices, comme Il veut » (Cor. 3/6), il attribue aux gens de l'interprétation ou exégètes (ahl al-ta'wil) l'égarement dans leur explication de l'acte de création ou, plus exactement, la donation des formes (tașīir).

D'après Ibn 'Arabī, seul le nom divin al-Mușawwir est chargé de donner des formes et aucun autre nom divin, même si les noms divins ne sont pas surajoutés à l'Essence divine ( $\underline{d} \bar{a} t)$. Il explique le tort des exégètes avec une certaine ironie pour montrer qu'ils seront interrogés sur leur interprétation le jour du jugement dernier, c'est-à-dire en voyant le ta'wīl (ma'āl ou destinée) de leur propre ta'wīl : "Quant aux exégètes, même s'ils s'accordent avec la science, ils ont tort en s'immisçant dans le ta'wïl. Ils ont commis un interdit auquel ils seront amenés à répondre le jour de la résurrection, eux et tous ceux qui parlent de Son Essence, Le transcendent de ce qu'Il a attribué à Lui-même, souscrivent au jugement de l'intellect plutôt que la foi et utilisent la spéculation dans leur connaissance du Seigneur ${ }^{96} . »$

Dans un autre texte, il met carrément en garde contre l'usage abusif de l'interprétation : «Il dit : s'ils s'en tiennent à l'apparent (zăhir) de leur Livre, ils ne le rejettent pas derrière leur dos. Ce qui leur cause tort est le ta'wïl. Sois prudent face à ses excès ${ }^{97}$ ! » Ces mises en garde ne sont proférées qu'à l'encontre du ta'wil 'aqlī, celui qui use et abuse de la spéculation dans la compréhension du texte coranique : «Dieu a dit que seul celui dont le cœur contient une aberration interprète les versets équivoques (mutašābih) selon sa spéculation ${ }^{98}$. "

Mais quel est le motif du ta'wìl ? Ibn 'Arabī ne se contente pas de dénoncer les abus de l'interprétation et l'usage de la vision spéculative (nazar) dans le commentaire des versets. Il veut surtout comprendre comment naît le désir d'interpréter et d'attribuer aux mots d'autres significations. C'est dans le chapitre 276 qu'il nous livre quelques éléments de réponse. La première remarque qu'il faut signaler est la distinction qu'il établit entre la science ('ilm) et l'interprétation ( $t a$ 'wìl). La science signifie la saisie de la chose telle qu'elle est en elle-même (per se), c'est-à-dire directement, sans qu'une cause s'interpose entre le

96. Fut., II, p. 407 (chap. 198).

97. Fut., IV, p. 400 (chap. 588).

98. Ibid., p. 527. 
sujet qui perçoit et l'objet perçu. Lorsque la confusion s'installe, c'est-à-dire dès qu'une chose prend la forme (șurra) d'une autre, le sujet connaissant se heurte aux exigences de l'interprétation. La perception imaginale joue ici un rôle prépondérant.

H. Corbin l'a rappelé dans son Imagination créatrice. Là où il y a imagination, il y a forcément du ta'wīl, car d'une part, les choses prennent l'apparence d'autres choses et, d'autre part, l'évidence et la certitude sont du ressort de la science. Or Ibn 'Arabī boude le ta'wīl en raison du labs ou iltibās qu'il provoque, c'est-à-dire la confusion ou l'ambiguïté ${ }^{99}$. Pour éviter ce labs, il préconise le ta'wïl kašfì (l'herméneutique illuminative), une lumière émanant du mystère qui pénètre dans la profondeur des choses afin de dévoiler leur réalité essentielle. C'est cette voie, indice de la science authentique, qui est prônée par les initiés.

En d'autres termes, ce n'est pas tant les réalités multiples et équivoques qui sont contestées, alors qu'elles sont les formes épiphaniques de la manifestation divine (tağallī), mais l'usage non approprié de l'intellect ('aql) pour les interpréter ou leur assigner une seule et unique signification. Le ta' wìl kašfi loué par Ibn 'Arabī est celui qui a pour moyen de perception et d'expression le cœur (qalb). Ce dernier est seul capable de saisir ce qui se fait et se défait dans les états spirituels $(a h w w \bar{l} l)$ et les réalités protéiformes.

Dans ce mode intuitif du ta'will, les sciences ne sont pas acquises par les arguments rationnels mais sont obtenues directement par inspiration, ce qu'Ibn 'Arabī appelle l'enseignement divin (itām, ta'lìm, ta'rîf, etc.) : «La connaissance de Dieu ne provient que de Son information ou de ce qu'Il fait connaître (ta'rif) à l'homme. Elle ne dépend pas de la vision spéculative. La seule personne qui accepte ce qu'Il fait connaître est le croyant ${ }^{100}$. » La foi (ìmān) a dans ce contexte une place importante dans le ta'wīl d'Ibn 'Arabī . Elle est lumière qui dévoile l'enseignement divin et science évidente procurant la certitude ${ }^{101}$. Afin de comprendre comment s'effectue l'enseignement émanant de Dieu comme principe herméneutique, il serait judicieux de se référer au chapitre 54 sur les allusions symboliques (išāāāt).

Ibn 'Arabī condense ici la somme de ses idées sur le ta'wìl. Il explique que l'allusion symbolique (išāra) est au soufisme ce que le commentaire (tafsìr) est à l'exégèse. Le mode intuitif mis en œuvre par les initiés est une sorte d'exégèse spirituelle qui a sa méthode et son vocabulaire. L'allusion symbolique émane d'elle même et l'expression ('ibāra) est visible dans le monde sous forme de signes érigés (āyāt) d'après le verset « Nous leur montrerons Nos signes dans l'univers (mot à mot : les horizons) et en eux-mêmes » (Cor. 41/53).

Le mot išāra a été choisi pour une raison doctrinale, car si les initiés avaient nommé leur interprétation des versets tafsìr, ils seraient alors dénigrés par les docteurs de la Loi. L'aspect elliptique de leur discours est une forme de protection (wiqāya) contre le déferlement des savants traditionnistes ('ulamā al-rusūm). Les sagesses qu'ils obtiennent par enseignement direct sont trop élevées pour être connues. Ils recourent alors à ce mode d'interprétation qui n'est qu'un genre particulier de tafsìr (on se rappelle de Haqā’iq al-

99. Fut., II, p. 596 (chap. 276).

100. Fut., IV, p. 7 (chap. 405).

101. Fut., II, p. 599 (chap. 277). 
tafsìr de Sulamī). Cette exégèse subtile (tafsīr) nécessite discrétion et préservation (satr) en employant les images et les symboles.

Ibn 'Arabī reproche aux savants traditionnistes leur manque de tolérance vis-à-vis des mystiques initiés, alors que leurs sciences sont acquises par instruction et effort spéculatif : « Ils ignorent que Dieu s'est chargé d'instruire certains de ses serviteurs dans leur secret intime, en leur enseignant ce qu'Il a révélé dans ses Livres et par la bouche de ses Prophètes. Ce qu'Il leur enseigne est la science authentique ('ilm șaḥih) émanant du Savant dont la perfection n'est jamais mise en cause par le croyant ${ }^{102}$. "

L'exégèse spirituelle fait découvrir le sens du texte en perpétuel renouvellement. Elle fait vivre la descente du Coran dans le cœur des initiés en remontant à son origine lorsqu'il a été révélé pour la première fois au Prophète. Ibn 'Arabī admet donc l'acception étymologique du ta'wìl qui remonte à la source, c'est-à-dire à l'expérience vécue ${ }^{103}$. Celleci consiste à obtenir la science par inspiration (ilhām) faisant allusion au propos d'Abū Yazīd al-Bisțāmī (m. 255/849) à l'adresse des fuqahā': « Vous avez pris votre science d'un mortel d'après un mortel et nous, nous avons obtenu notre science du Vivant qui ne meurt jamais. »

L'allusion symbolique (ǐ̌āra) comporte plusieurs éléments qui la distingue des autres formes herméneutiques:

1- Elle est exégèse intuitive dont le mode d'opération est le ta'wïl kašfī, l'herméneutique illuminative ou le dévoilement.

2- Elle est enseignement divin obtenu par inspiration (ilhām) comme le Prophète a obtenu les préceptes divins par révélation (wahy).

3- Elle constitue un système de signes (vocabulaire, convention, etc.) dont l'usage est rigoureusement codifié.

4- Elle est caractérisée par la pluralité des significations, en ce sens que le mot contient plusieurs aspects (wuğūh) permettant une multitude de compréhensions.

Certains éléments lexicographiques sont exposés dans le chapitre 418 dans lequel Ibn 'Arabī distingue entre la science ('ilm) qui s'attache aux significations détachées des mots, et la compréhension ( $f a h m)$ qui se rapporte aux termes ${ }^{104}$. Le fahm est plus global que le 'ilm, car le mot auquel il s'attache comporte le sens voulu par le locuteur et plusieurs significations relatives à la terminologie (la langue conventionnelle); alors que le 'ilm porte uniquement sur la terminologie et ignore l'intention du locuteur ${ }^{105}$.

Dans l'exégèse spirituelle, les initiés qui comprennent la parole divine sont ceux qui obtiennent la sagesse (hikma) et le détail du prône (faṣl al-hițāb) d'après le verset «Et Nous renforçâmes son royaume et lui donnâmes la sagesse et le détail du prône (ou la faculté de bien juger) »(Cor. 38/20). La sagesse est mettre chaque chose à la place qui lui

102. Ibid.

103. Fut., III, p. 453 (chap. 372).

104. Fut., IV, p. 25 (chap. 418).

105. Fut., III, p. 121 (chap. 332). 
convient ${ }^{106}$. Sur le plan de l'exégèse spirituelle, c'est donner aux versets la signification adéquate voulue par Dieu. Ibn 'Arabī n'exclut pas le risque d'intrusion d'idées étrangères à l'esprit du texte sous formes de doute ou d'incertitude (šubha) attribuant à un verset un sens équivoque. Les doutes (šubuhāt) jouent le rôle de pirates dont les armes sont la spéculation et l'interprétation.

Ibn 'Arabī développe cette image dans le chapitre 521 à propos de la crainte pieuse ou la piété (taqwā). Celle-ci protège l'initié des aléas du voyage. Etant donné que chacun effectue un voyage particulier ${ }^{107}$, la voie sur laquelle il chemine est entourée de dangers. Dans le

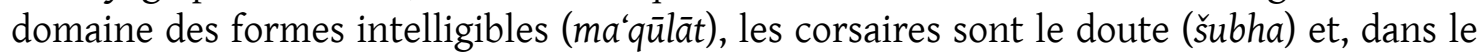
domaine des prescriptions légales (mašrū ‘āt), ils représentent l'interprétation des versets équivoques (mutašābihāt). Seul l'initié est à l'abri de ces risques grâce à la crainte pieuse (taqwā). Il reçoit les voyageurs en assimilant avec équité toutes les sciences rationnelles et légales, mais ne voyage pas. La taqwā est les vivres qui lui épargnent les vicissitudes du parcours d'après le verset « Et prenez vos provisions; mais vraiment la meilleure provision est la piété » (Cor. 2/197).

Ibn 'Arabī décrit cette image en ces termes ${ }^{108}$ : la terre ferme (barr) représente l'aspect apparent (zāhir) et la mer (baḥr) symbolise le sens ésotérique (bātin). Le voyage en mer signifie l'usage de la spéculation et du ta'will pour interpréter les préceptes légaux. Le voyage en terre ferme veut dire se contenter de l'aspect extérieur de la Loi (šarīa). Les soufis (les mystiques initiés) effectuent les deux voyages sur un plan de l'être : le voyage terrestre est les formes épiphaniques qui se manifestent à eux, et le voyage en mer désigne l'interprétation ésotérique de ces formes. Comme les gens de la spéculation, les soufis ne sont pas à l'abri des dangers que provoque le voyage, c'est-à-dire la confusion (labs) face aux théophanies (tağaliyyāt) récurrentes. Pour faire face à ces intrusions spéculatives ou à l'égarement dans la perception des théophanies, Ibn 'Arabī érige l'enseignement divin en solution doctrinale.

Le commentaire qu'il fait du verset (Cor. 2/7) ${ }^{109}$ reste fidèle à la lettre. Il montre que l'explicite (muhkam) et l'équivoque (mutašābih) doivent être pris dans les limites de l'énoncé coranique. Les enracinés dans la science (rasihūn fì l-ilm) connaissent son interprétation ( $\left.t a^{\prime} w \bar{l} l\right)$ grâce à l'enseignement divin, et non pas en vertu d'un effort spéculatif. Ils adhèrent à ses vérités par la lumière de la foi (dans le verset «āmanna bihi») et admettent les deux aspects du Coran (explicite et équivoque), à l'instar des initiés qui prennent la mer et la terre, ou bien ils sont emmenés en voyage malgré eux, à l'exemple du voyage nocturne du Prophète (isrā') et son ascension céleste (mi'rāğ) ${ }^{110}$. Ils réunissent ainsi l'expression ('ibāra)

106. Fut., II, p. 163 (chap. 88).

107. Sur la notion du voyage et ses implications spirituelles, v. IBN 'ARABī Kitāb al-isfār 'an natā’iğ al-asfār, Haydarabad, 1948 ; Le dévoilement des effets du voyage, trad. D. Gril, Paris, éd. de l'Éclat, 1994.

108. Fut., IV, p. 164 (chap. 521).

109. Voir par exemple Fut., I, p. 194-95 (chap. 27) ; Fut., III, p. 542 (chap. 388).

110. K. al-isfār, p. 3 ; trad. D. Gril, p. 9. 
et l'allusion (išāra), l'acquisition (kasb) et le don (wahb), l'extérieur (zāhir) et l'intérieur (bātinin), etc.

Cette réunion n'est pas un mécanisme rationnel mais une sorte de ta'wïl kašfí qui accède à l'origine dans la science divine, c'est-à-dire en connaissant la véritable signification que Dieu a établie dans Son Livre. Le ta'wīl kašfì passe nécessairement par des modalités de perception qui ne sont pas le sensible ou l'intelligible, mais la perception imaginale (hayāl) qui s'opère au niveau des songes. C'est pourquoi le ta'wïl est souvent associé, chez Ibn 'Arabī, au rêve (hulm) et à la vision imaginale (ru'yā) ${ }^{111}$.

Le mode d'expression du ta'wīl est le ta'bìr qui croise dans sa racine étymologique avec l'expression ('ibāra), le passage ou la traversée ('ubūr), l'observation (i'tibār), la méditation ('ibra). C'est autour de la racine '- $B-R$ que notre auteur examine le fondement et la protée du ta'wìl. Il emploie rarement le mot mağāz qui est la métaphore ${ }^{112}$, car ce mot a pris dans la pensée musulmane classique une connotation théologique (kalām) empreinte d'investigation spéculative. Le cas des mu'tazilites est significatif. La notion de ta'bìr comprend l'entreprise herméneutique ( $\left.t a^{\prime} w i \bar{l}\right)$ et la transposition symbolique ( $\mathrm{ramz}$ ). Elle entretient une relation étroite avec la notion de mițāl telle qu'elle a été exposée par Ġazālī.

Ibn 'Arabī explique que les notions de symbole ( $\mathrm{ramz})^{113}$ et de modèle (mițāl) ${ }^{114}$ renvoient à quelque chose en vertu d'une relation corrélative : « Dieu interpella Ibrāhīm (Abraham) en disant : Ô Ibrāhīm, tu as ajouté foi au songe ! Il ne lui a pas dit : "Tu a eu raison de penser que dans ce songe il s'agissait de ton fils", car il ne l'avait pas interprété et s'en était tenu à l'apparence de ce qu'il avait vu, alors que le songe requiert une interprétation. C'est pour cela que le Maître a dit: si vous êtes capables d'interpréter le songe (Cor. 12/43). Le terme ta'bìr exprime le passage de la forme de ce qu'il avait vu à une autre réalité ${ }^{115}$. »

Les songes nécessitent donc l'interprétation permettant de saisir la signification sousjacente des images vues. L'exemple le plus commenté par Ibn 'Arabī est l'image du lait (laban) qui signifie la science ('ilm) par transposition symbolique. Il cite, à cet égard, le hadith « Alors que je dormais, j'ai reçu un verre de lait. J'en ai bu jusqu'à ce que le lait sorte de mes ongles, puis j'ai donné le reste à 'Umar Ibn al-Hatțāb ${ }^{116}$. Ô Envoyé de Dieu, comment l'avais-tu interprété ? Il a dit : la science ${ }^{117}{ }$. Le songe doit être interprété afin de ramener l'image perçue à sa source spirituelle.

Car, selon Ibn 'Arabī, le rêve a tendance à pervertir la science qui est une qualité spirituelle en la transposant dans une image sensible (le lait) rendue subtile par le pouvoir

\footnotetext{
111. Sur l'étymologie du ta'wīl comme mode d'expression et de signification qui va du locuteur à l'auditeur moyennant terme la perception imaginale, v. Fut., III, p. 453-54 (chap. 372).

112. Sur le mağāz v. EI² (l'Encyclopédie de l'Islam, $2^{e}$ éd., Paris-Leyde, J. Brill, Maisonneuve \& Larose, 1986), V, p. 102124.

113. Fut., I, p. 189 (chap. 26).

114. Sur la notion de mitāl chez Ibn 'Arabī v. Fut., II, p. 432 et 470 (chap. 198) et Fut., III, p. 260 (chap. 357).

115. Fuṣ., I, p. 85-6 ; Le Livre des chatons des sagesses, trad. Charles André Gilis, Beyrouth, Bouraq, 1997, p. 188.

116. Ce personnage est l'un des principaux compagnons du Prophète Mahomet.

117. Buhārī, Sahīh, Kitāb al-'ilm (Le livre de la science), I, p. 31.
} 
de l'imagination ${ }^{118}$ : "Tout ce qui advenait se nomme "le monde imaginal" et c'est pour cela qu'il convient de l'interpréter; la chose qui, par elle-même, possède telle forme apparaît sous une forme différente. L'interprète, si son interprétation est juste, passe de la forme que voit le dormeur à celle de la chose véritable. Par exemple, la manifestation de la science sous la forme du lait : le Prophète passa, dans son interprétation, de la forme du lait à celle de la science; il interpréta en disant que la forme visible du lait devait être transposée et amenée à la forme (principielle et invisible) de la science ${ }^{119}$.

Mais quel est le rapport entre le symbole (le lait) et ce qu'il symbolise (la science) ? S'agit-il d'un rapport d'identité ou de différence ? En réalité, le symbolisme est caractérisé par un paradoxe : le symbole ressemble au symbolisé sur le plan imaginal (le lait est la science) et ne ressemble pas à lui sur le plan réel (le lait n'est pas la science). Toute la littérature de l'immanence (tašbìh) et de la transcendance (tanzìh) tourne autour de ce paradoxe qui a suscité dans les disciplines théologiques (kalām) et philosophiques ( $f a l s a f a)$ de violentes polémiques. Si les théologiens ont tenté de résoudre cette antinomie par les moyens dialectiques et linguistiques (rôle de la grammaire), les mystiques initiés empreints de théosophie comme Ibn 'Arabī prennent ce paradoxe dans ce qu'il est, sans interprétation excessive ou tentative de conciliation à la Hegel.

Tel est le cas de la science ('ilm) et de la connaissance (ma'rifa) qui sont identiques sur le plan terminologique, mais différentes au niveau doctrinal. Ibn 'Arabī invoque le problème de la nomination et les circonstances syntaxiques et sémantiques dans lesquelles elle est appliquée ${ }^{120}$. Doit-on dire science ou connaissance ? De quelle manière peut-on déceler l'identité et la différence entre les deux notions? Ou, en termes d'Ibn 'Arabī, « les connaissances sont-elles les sciences ou bien leurs réalités sont différentes comme les différences de leurs noms ${ }^{121}$ ? »Certains ont vu qu'il est hors de propos de vouloir insister sur les nuances philologiques: "En réalité, ces distinctions sont fort artificielles, et l'on doute même qu'une étude sémantique des deux termes fondée sur de vastes dépouillements, ne jette quelque lumière sur ce problème, tant les emplois qu'en font les auteurs sont personnels et variables selon les disciplines ${ }^{122}$. "

Cependant, l'évolution du 'ilm et de la ma'rifa dans la pensée islamique et, en particulier, le soufisme présage des emplois autres que personnels, étant donné que l'usage de ces deux notions a changé en fonction d'une nécessité doctrinale, et pas seulement d'après les appréciations individuelles. Par exemple, le soufisme classique ${ }^{123}$ depuis Ğunayd (m. 298/911) a favorisé la márifa comme approche pratique par la mise en application des

\footnotetext{
118. Fut., IV, p. 240-41.

119. Fus., I, p. 99-100 ; trad. Gilis, I, p. 243-44.

120. Sur les multiples définitions de la science et de la connaissance v. Fut., II, p. 318-19 (chap. 177) et Kitäb ali' lām bi išārāt ahl al-ilhām (Traité d'information sur les allusions symboliques des gens doués d'inspiration), p. 5, in Rasā'il.

121. Fut., III, p. 232 (chap. 351)

122. $E I^{2}$, III, p. 1161, article «'Ilm».

123. Cf. le riche exposé de R. Arnaldez dans EI², VI, p. 554-56, article « Ma'rifa »; et Franz Rosenthal, Knowledge Triumphant. The Concept of Knowledge in Medieval Islam, Leyde, J. Brill, 1970.
} 
préceptes de la Loi. La ma'rifa signifie ici sagesse pratique (hikma) pour l'intérêt que les soufis portent à l'œuvre pieuse ('amal).

Les débats théologiques ne les passionnent pas, pas plus que les réflexions sur la morale. Les manuels écrits sur les stations (maqāmāt) et les états spirituels ( $a h w \bar{a} l)$ sont destinés à l'action morale. À partir de Ġazālī, c'est-à-dire avec l'introduction de la théologie et de la philosophie dans le corps de la doctrine, les deux notions ont pris une acception logique au sens d'une abstraction formelle : la science porte sur ce qui est global et synthétique (kulli) et la connaissance concerne le particulier $(\check{g} u z ' \grave{\imath})^{124}$.

Ces définitions ont affecté la nature des approches doctrinales de la connaissance de Ġazālī à Ibn 'Arabī et au-delà. En effet, la notion de la science a gagné vite du terrain au détriment de la connaissance pour des raisons à la fois épistémologiques (on ne pourrait pas se passer du discours philosophique tributaire de l'Organon aristotélicien) et doctrinales (on ne pourrait pas non plus s'écarter de l'enseignement coranique qui fait autorité). Tout en conservant l'essentiel de ces idées philosophiques, Ibn 'Arabī formule sa conception en fonction d'un impératif religieux : le 'ilm est un attribut divin, alors que la ma'rifa ne l'est pas. Dieu se nomme Savant ('Ālim) et non pas Connaissant ('Ārif). Ce dernier est l'attribut de l'homme qui saisit une infime partie de connaissances d'après le verset «Et on ne vous a donné que peu de science » (Cor.17/85).

Le Coran emploie la science comme qualité supérieure «Parmi les serviteurs de Dieu, les savants sont seuls à Le redouter » (Cor. 35/28) ; "Dis: Seigneur! Accroît en moi la science » (Cor. 26/197).

Ibn 'Arabī admet certes l'identité conceptuelle des deux notions: "La science et la connaissance sont similaires dans les termes et la réalité et dans le fait que savoir signifie dévoiler la chose telle qu'elle est ${ }^{125}$. » Mais il se tient au texte coranique qui exalte la qualité du savant. Par ailleurs, bien qu'elles soient similaires conceptuellement, les deux notions sont différentes quant à la fonction exercée. Ce n'est pas tant l'identité sémantique qui pose problème que l'usage théologique ou anagogique que l'on fait des deux notions. On a l'habitude de dire aujourd'hui, et avec justesse d'ailleurs, que "meaning is use", c'est-à-dire que le mot requiert sa signification en fonction du rôle qu'il joue dans un système donné. Si nous examinons de près la nature lexicographique des deux notions, nous pouvons dire qu'elles se distinguent non pas sur le sens qui leur est donné d'après les disciplines et les catégories de personnes, mais en fonction de l'usage.

L'exemple concret, sans aucune trivialité, qu'Ibn 'Arabī mentionne est tout à fait pertinent. La science et la connaissance sont comparables à l'eau et à la glace. L'eau et la glace sont deux choses semblables (la même substance), mais la caractéristique de l'eau dans sa liquidité est différente de celle de la glace dans son aspect solide ${ }^{126}$. L'usage est, à

124. Sur les définitions logiques et philosophiques de ces notions dans la pensée islamique v. IBN SīnĀ (Avicenne), Kitāb al-Nağāāt, éd. Mağ̄̄id Fahry, Beyrouth, Afaq, 1982 ; ĠAzĀL̄̄, Mi'yār al-'ilm, éd. critique Sulaymān Dunyā, Le Caire, éd. Dār al-ma‘ārif, 1961 (" Dahhā’ir al-'arab », 32); Mahakk al-naẓar, éd. N. Na‘sānī, Beyrouth, éd. Dār al-Nahḍa, 1966.

125. IBN ‘ARABĪ, Mawāqi al-nuğūm, Le Caire, 1965, p. 26 et 32 ; v. aussi Fut., IV, p. 55 (chap. 441).

126. Fut., IV, p. 130 (chap. 493). 
son tour, différent. Se désaltérer en buvant de l'eau n'est pas semblable à la réfrigération d'un liquide au moyen d'une glace.

La connaissance est-elle une science particulière comme la glace est une eau congelée? La comparaison est purement métaphorique. En étudiant le symbolisme de chaque notion, nous pouvons apercevoir les nuances non détectables par notre dispositif théorique trop technique et excellemment glacial !

R. Arnaldez doute qu'il y ait une différenciation significative chez Ibn 'Arabī : « Il ne semble pas qu'Ibn 'Arabī distingue dans leur emploi les mots de science et de connaissance. Pour lui, il y a une ma'rifa qui est atteinte par la lumière de l'intelligence (bi nūr al-'aql) [...]. On voit donc qu'il s'agit d'une connaissance rationnelle, c'est-à-dire d'une science. D'autre part, il y a une ma'rifa qui est atteinte par la lumière de la foi (bi nūr al-īmān), grâce à laquelle l'intelligence ('aql) saisit l'Essence et les qualifications que Dieu rapporte à Lui-même. C'est cette seconde márifa qui serait celle des mystiques ${ }^{127}$. »Cette différence a assurément une pertinence doctrinale, mais elle ne nous montre pas les nuances qui y sont impliquées. Le symbolisme appliqué pourra nous livrer quelques secrets.

Lorsque Ibn 'Arabī parle dans le chapitre 249 du breuvage (šurb), il en recense quatre sortes: l'eau, le lait, le vin et le miel ${ }^{128}$. Ces breuvages sont déduits du verset «Voici la description du paradis qui a été promis aux pieux : il y aura là des ruisseaux d'une eau jamais malodorante, et des ruisseaux d'un lait au goût inaltérable, et des ruisseaux d'un vin délicieux à boire, ainsi que des ruisseaux d'un miel purifié » (Cor. 74/15).

L'eau symbolise les significations spirituelles détachées de la matière. Dans le Kitāb al'abādila ${ }^{129}$ (Le livre des noms propres commençant par 'Abd), elle est associée d'une part, à la science des prescriptions légales ('ilm al-rusūm) et, d'autre part, aux esprits détachés du monde sensible s'il s'agit de l'eau de la pluie, et aux éléments composés s'il s'agit de l'eau des ruisseaux. Les éléments inférieurs dépendent des esprits supérieurs comme les ruisseaux se remplissent grâce à la pluie.

Le lait représente la science de l'unicité (tawhīd) et l'accès aux secrets ésotériques réservés aux prophètes et aux saints.

Le vin est le symbole des sciences divines inaccessibles par l'effort spéculatif. Il désigne la science des états spirituels ('ilm al-ahwwāl).

Enfin, le miel est indice de l'inspiration et de la foi. Un examen attentif à cette transposition symbolique nous renvoie à la classification des sciences procédée par Ibn 'Arabī dans l'introduction des Futūhạt : la science de l'intellect ('ilm al-'aql), la science des états spirituels ('ilm al-ahwāl) et la science des secrets ésotériques ('ilm al-asrār). Celle-ci se divise en deux espèces : la science de l'intellect par un mode réceptif et intuitif, et une autre science qui comprend d'une part le goût initiatique (dawq) et, d'autre part, l'information (habar) rapportée par les prophètes nécessitant l'adhésion et la foi.

Reprenons les correspondances symboliques: l'eau correspond à la science de l'intellect, le vin désigne les états spirituels incluant la modalité du goût, le lait symbolise les

127. EI ${ }^{2}$, op. cit., p. 555.

128. Fut., II, p. 550.

129. Iвn 'ARABī, Kitāb al-'abādila, éd., introd. et notes par 'Abd al-Qādir A. 'Ațā, Le Caire, 1969, p. 87. 
secrets ésotériques sous deux catégories : eau douce (car le lait est essentiellement une eau) désignée par l'aspect réceptif et intuitif de l'intellect, et une autre catégorie qui comprend deux espèces : un état spirituel ayant un goût subtil et noble, et une information prophétique (habar) nécessitant la foi. Le miel représente ces deux espèces du secret ésotérique.

Pour une raison heuristique, le schéma que nous proposons correspond à ces subdivisions. Ibn ‘Arabī n'a pas expressément mentionné ces correspondances symboliques, mais nous les avons déduit de la comparaison que nous avons faite entre ces symboles et les sciences.

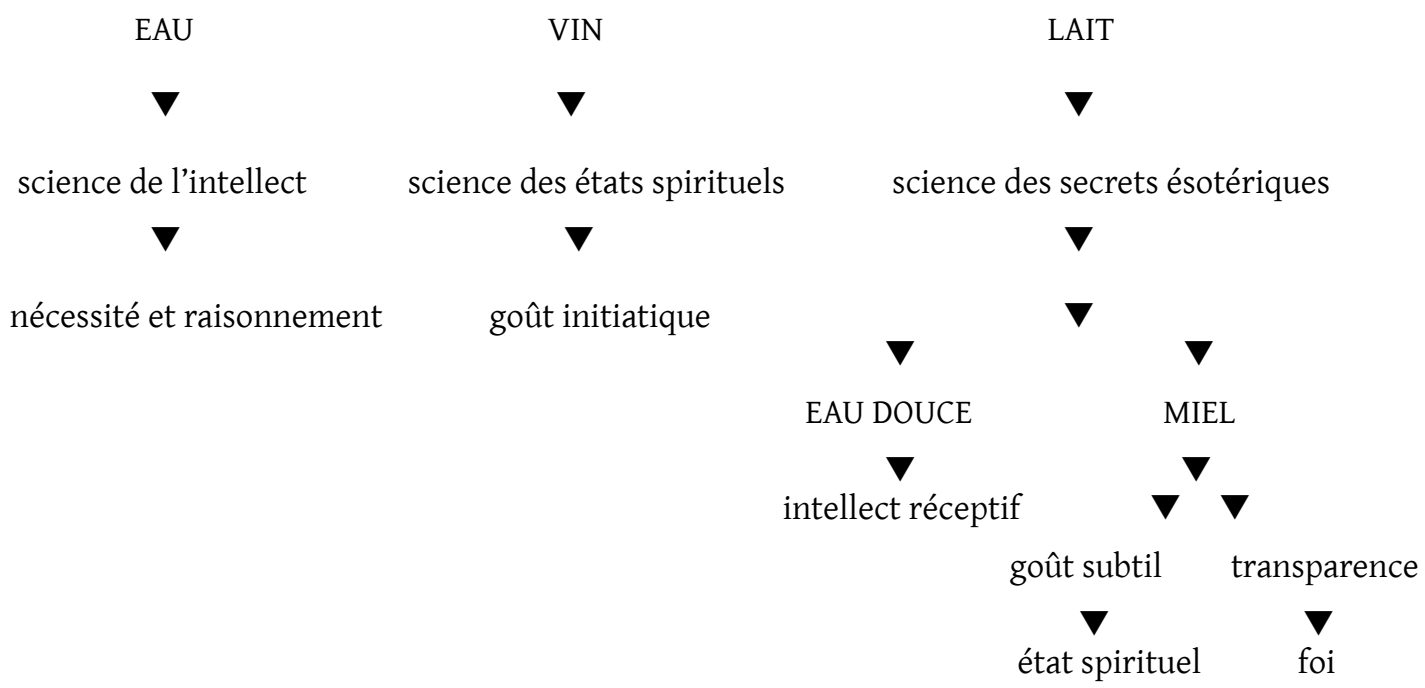

D'autres symboles désignant la science sont mentionnés dans le chapitre 279 : le coup subit (darba), le clin d'œil synoptique (nazra) et le jet (ramya) ${ }^{130}$. Ces actes attribués au Prophète dans le Coran sont des manifestations théophaniques porteuses de connaissances spirituelles. Celles-ci ne sont pas obtenues par l'effort spéculatif mais émanent directement de l'enseignement divin. Elles sont du ressort du cœur (qalb) ou de l'intellect réceptif ('aql $q \bar{a} b i l)$. Ces actes elliptiques comportent des sciences considérables, alors qu'ils ont du point de vue humain une temporalité infinitésimale.

Comment des sciences et des sagesses peuvent s'établir dans le cœur de l'initié dans un temps aussi fugace qu'une fraction de seconde ? Ibn 'Arabī en a fait l'expérience comme il le dit dans le prologue des Futūhāa . À partir d'une expérience dense et prompte comme le clin d'œil, une œuvre monumentale a surgi : un univers de sagesses issu d'un atome imperceptible! Ces moments elliptiques correspondent au goût initiatique (dawq). Audelà, ce n'est plus le goût mais le breuvage (šurb) ${ }^{131}$ en fonction des boissons (eau, vin,

130. Fut., II, p. 608 et aussi Fut., III, p. 39 (chap. 310).

131. Fut., II, p. 550 (chap. 249). 
lait, miel), c'est-à-dire en fonction des sciences acquises : spéculatives, légales, initiatiques, ésotériques, etc.

La connaissance (márifa) possède, elle aussi, un symbolisme qui lui est propre. Ibn 'Arabī parle toujours dans le cadre de l'énoncé coranique lorsqu'il explique les racines de la márifa. Il fait référence à la halte de 'Arafa (al-wuqūfbi 'Arafa) dans les chapitres 71 et 72.

'Arafa est le nom d'un mont près de Médine auprès duquel les pèlerins prient et invoquent les louanges de Dieu. Pourquoi le nom 'Arafa? Ibn 'Arabī cite un hadith selon lequel Ibn 'Abbās s'interroge pourquoi 'Arafa a été nommé ainsi ? La réponse du Prophète est que l'Ange Gabriel a informé Abraham dans le lieu où ce dernier se trouvait (c'est-à-dire l'actuel 'Arafa) en lui disant " Tu as connu ('arafta) ${ }^{132}$ ». Le mont 'Arafa tire sa nomination de cette anecdote. 'Arafa et ma'rifa ne sont pas étrangers l'un de l'autre sur le plan doctrinal.

Voici comment Ibn 'Arabī explique la correspondance symbolique moyennant la grammaire pour aboutir à la conclusion d'après laquelle l'enseignement divin est le seul bien-fondé herméneutique et cognitif : «La connaissance (márifa) est transitive vers un seul et unique [participe passé] passif (tata'addā ilā maf'ūl wāhid) et toi tu es à 'Arafa ; et la science ('ilm) est transitive vers deux [participes passés] passifs (yata'addā ilā maf'ūlayn)

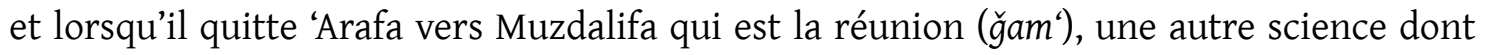
l'être connu est Dieu (Allāh) pendant que l'être connu à 'Arafa était le Seigneur (Rabb) et ce complément d'objet (mafül) que tu obtiens en ce jour est ta science sur ton Seigneur, non sur toi-même et tu connais ainsi Dieu par Dieu ${ }^{133}$. "

Ce texte condense une somme importante de vérités sur la dimension cognitive chez Ibn 'Arabī. La science est rapportée généralement à la divinité (ulūhiyya), alors que la connaissance est étroitement liée à la seigneurie (rubübiyya). La science représente la station de la réunion (ğam`), c'est-à-dire l'unité intrinsèque (ahadiyya) en dehors de toute réalité créaturelle. La connaissance se rapporte plutôt à la station de la séparation (tafriqa) qui concerne la multiplicité des noms divins et leur attachement au monde de la création. Ainsi 'Arafa est le temple symbolique de la ma'rifa qui est de nature contemplative. Il n'y a connaissance que là où il y a contemplation, c'est-à-dire vision clairvoyante qui va au-delà des écrans pour dévoiler la réalité essentielle des choses et de leur mystère.

\section{CONCLUSION}

Ce qu'il faut essentiellement retenir de l'exégèse soufie est le pouvoir du dévoilement (kašf) dans la façon de percer les mystères et aller au-delà des limites cognitives que l'intellect atteint par sa spéculation. L'explication que nous avons donnée de l'interprétation chez Ibn 'Arabī nous force à maintenir le ta'wīl dans les limites de l'adjectif, étant donné que le substantif ta'wïl n'existe pas comme savoir théorique et cohérent au sens d'une discipline autonome. Ainsi, nous pouvons dire qu'il existe une "orientation herméneutique" chez Ibn 'Arabī sous forme de commentaire, d'allusion et de symbolisation, mais il n'existe pas une "herméneutique" comme branche autonome du savoir canonique. De même en ce qui concerne l'aspect allégorique ou anagogique de la doctrine d'Ibn 'Arabī. Il existe assurément

132. Ibn Hanbal, Musnad, I, p. 298.

133. Fut., I, p. 360 (chap. 68). 
un sens "ésotérique" prêté aux versets coraniques spécifiquement et à la tradition généralement, mais un sens "ésotériste" aux couleurs hermétiques et kabbalistiques est difficilement détectable. Cette séparation entre "l'adjectif" et "le substantif" nous épargnera les interprétations fallacieuses du texte d'Ibn "Arabī ou de tomber dans des contresens mal assumés, surtout si nous savons qu'aujourd'hui à cause des conclusions hâtives tirées de notre lecture de l'héritage mystique, des procès d'intention à l'encontre de cet héritage ont été formulés. 